\title{
Positive Youth Development through a Co-Designed Modified Boxing Program
}

\author{
Paul Perkins ${ }^{1,2,3}$, Allan Hahn' ${ }^{1,4,5}$ \\ ${ }^{1}$ University of Canberra, Canberra, Australia \\ ${ }^{2}$ Ngunnawal Centre, University of Canberra, Canberra, Australia \\ ${ }^{3}$ Boxing Australia Limited, Canberra, Australia \\ ${ }^{4}$ Queensland Academy of Sport, Brisbane, Australia \\ ${ }^{5}$ Griffith University School of Engineering, Brisbane, Australia \\ Email: paul.perkins@uni.canberra.edu.au
}

How to cite this paper: Perkins, P. and Hahn, A. (2020) Positive Youth Development through a Co-Designed Modified Boxing Program. Open Journal of Social Sciences, 8, 148-199.

https://doi.org/10.4236/jss.2020.81013

Received: December 13, 2019

Accepted: January 11, 2020

Published: January 14, 2020

Copyright (c) 2020 by author(s) and Scientific Research Publishing Inc. This work is licensed under the Creative Commons Attribution International License (CC BY 4.0).

http://creativecommons.org/licenses/by/4.0/

\begin{abstract}
A modified boxing program in which youth and adults participated together ran for almost five years at an Australian community youth club. It was initially focused on preparing participants for occasional modified boxing competitions in which impacts to the head and neck were prohibited and any forceful impacts were penalized. The Head Coach of the program initiated regular small-group and individual discussions with participants and used the outcomes to guide program iteration. The participants became co-designers of the program and therefore architects of their own sport experience. This led to substantial changes in the nature of the program, with interpersonal competition progressively de-emphasized and eventually almost entirely removed. Increased attention was directed to building a cohesive, inclusive community and engaging in cooperative endeavours that provided a shared sense of purpose. Natural adult mentors emerged, and some adolescents took on peer leadership roles. Through a partnership between the club and a local university, program participants became involved in diverse research activities aimed at program improvement. Young program participants began to anecdotally report obtaining broad-ranging benefits from the program, and these reports were subjectively corroborated by parents and natural mentors. To determine the nature of any such benefits, we examined records of discussions that the Head Coach had logged in a detailed journal over the course of the program. We targeted a purposeful sample that included six young program participants and twelve adults who had varying program connections. Thematic analysis performed on the records of discussions with the selected subjects revealed that the most common perceived benefits that young people derived from the program were increased determination, increased self-confidence
\end{abstract}


and enhanced leadership skills. Specific program features most clearly associated with these outcomes were fostering of positive and supportive relationships, collaborative involvement of the young people in determining program directions and provision of opportunities for positive observational learning. These findings are consistent with published literature and contemporary theories on positive youth development. Although positive youth development was not the explicit objective of the modified boxing program, the establishment of functional youth-adult partnerships and co-design procedures in the program environment caused the program to take on characteristics that research has identified as critical to attainment of positive youth development outcomes.

\section{Keywords}

Box'Tag, Co-Design, Community Sport, Modified Boxing, ModBox, Positive Youth Development, Sport for Development, Youth-Adult Partnership

\section{Introduction}

From 2012 to 2016 inclusive, a modified boxing program was run at a Police Community Youth Club (PCYC) in Canberra, Australia, with the first author of this paper as its Head Coach. The original objective was to increase the number of participants in Canberra PCYC Boxing while also advancing the concept of modified boxing. During its course, however, the program gradually evolved to increasingly take on characteristics that promoted youth development. This paper aims to describe what occurred, assess the eventual effectiveness of the program as a vehicle for youth development, and view the outcomes through the lens of contemporary youth development theories.

\section{Background to Development of Modified Boxing Program}

The first author of this paper has a long history of involvement in conventional boxing, beginning from 1978. After competing as an amateur boxer, he moved into coaching, where he worked with athletes of all levels from novice to international. In 2009, he obtained an appointment as a Boxing Coach at the Australian Institute of Sport (AIS). During the following year, he combined the AIS role with a position as Head Coach of the Kiribati boxing team that competed at the Commonwealth Games in Delhi. He subsequently received the highest level of coaching accreditation available from the International Boxing Association (the international peak body for amateur boxing).

Toward the end of 2010, the AIS Boxing program closed, and the first author of this paper took up a new position as Head of Boxing at the Canberra PCYC. As a key performance criterion of the new position, he was required to increase participation in the program well beyond the existing level of 10 regular attendees. Over the following year, he implemented multiple initiatives aimed at 
meeting this requirement, but with very limited success. A need for a different approach to the task of increasing participation therefore became evident.

While at the AIS, the first author had become aware of the emergence in Australia of a modified form of boxing known as Box'Tag. The second author of this paper, who was then employed as a sport scientist at the AIS, had been pursuing the development of technologies to support the modified form [1], and AIS boxers and coaches had frequently assisted with field trials. In Box'Tag, impacts to the head and neck were prohibited, any impacts judged to have exceeded a moderate level of force were penalized, and use was made of automated electronic scoring technology that rewarded rapid rather than forceful punching [2]. A Box'Tag program had been successfully operating at a Sydney boxing and fitness club since 2006, with competitions resembling amateur boxing events held several times each year.

In light of the above awareness, the first author decided to implement a Box'Tag program at the Canberra PCYC as an adjunct to the conventional boxing program. He enlisted the help of the second author in this task. The Box'Tag program immediately proved popular, and within a few months attracted more than 10 times as many participants as the conventional boxing program. Since the Canberra PCYC management group saw this as an important step toward achievement of overall organisational goals, a decision was subsequently taken that Box'Tag should become the sole focus of the Canberra PCYC Boxing program, with conventional boxing discontinued. The rationale for this decision was that the sole focus would allow the first author to concentrate all his attention on refining the Box'Tag program to further increase its appeal.

\section{Description of Modified Boxing Program and Its Evolution}

The standalone Box'Tag program was officially launched in January 2012. From its outset, two training sessions were run on each of the five weeknights so that participants could choose times that fitted best with their other commitments. On three of the weeknights, the sessions were focused primarily on physical conditioning. On the other two nights, the emphasis was on the learning of Box'Tag-specific skills. Participants were able to vary both the number of sessions and the particular sessions that they attended from week to week. The initial notion was that participants would prepare for occasional public Box'Tag competitions.

The structure of the training sessions was derived from the prior coaching experience of the first author. Notably, the participants were always referred to as "athletes" even though many of them had no background in high-performance sport. They were expected to conduct themselves accordingly. There was a designated area for placement of training bags, clothing and other equipment. A training "dress code" was enforced and bringing of water bottles to sessions was mandatory. The importance of punctuality was highlighted, and there was an athlete line-up at the beginning and end of each session. Conversation during 
sessions was encouraged, but the need to always pay careful attention to coach instructions was stressed.

Although conducted in a Youth Club setting, the Canberra PCYC Box'Tag program was not confined entirely to youth, and from the beginning the athletes ranged in age from 10 to 60 years. People below the age of 30 years did, however, predominate. Females always comprised over $50 \%$ of the athletes. There was wide variation in physical abilities within the group. Two former Australian champion amateur boxers and a current professional boxer were there from the outset and became long-term program adherents. Several other people with a history of involvement in boxing were also among the participants, along with accomplished performers from various other sports. By contrast, there were quite a few participants who had little or no sporting background and certainly no prior experience of boxing. One participant was blind. All these people trained together. It was common to have 25 - 30 participants in a session, and there were occasions on which the number exceeded 60 .

Another potentially salient feature of the program was that it quickly became a setting for research and development (R\&D) activities directed toward continual program refinement and general progression of the Box'Tag concept. At first, the activities were concentrated largely on evaluation and iteration of the automated scoring technology [2], but other focus areas were soon incorporated and, after a few months, an agreement between the Canberra PCYC and the University of Canberra led to formal recognition of the PCYC as a Field R\&D Centre (Figure 1). The authors of this paper worked closely together on several projects and the first author gradually became interested in the prospect of undertaking formal research training. To this end, he gained admission to postgraduate studies at the University of Canberra and subsequent approval to pursue a research question as to whether a modified form of boxing could achieve significant community uptake. His role within the Canberra PCYC Box'Tag program therefore became that of practitioner/researcher, and program athletes consented (either directly or through parents or guardians) to become participants in a research project.

It was always intended that program athletes would be closely consulted concerning their experiences and impressions of the program so that structure and content could be adjusted to their needs, but with the advent of the formal research project this consultation took on new dimensions. Group discussions were held after every training session and, in addition, one-on-one conversations were regularly initiated. On a few occasions, athletes were invited to complete written surveys and/or in-depth interviews. Comments made by the athletes were recorded in a comprehensive journal maintained by the first author, as were the details of testing of equipment or technologies designed for employment in the modified boxing setting. The process of entering the comments, together with repeated scrutiny of the entries, ensured that the coach/researcher was highly conscious of the feed back and could use it effectively to guide the planning of future sessions. 


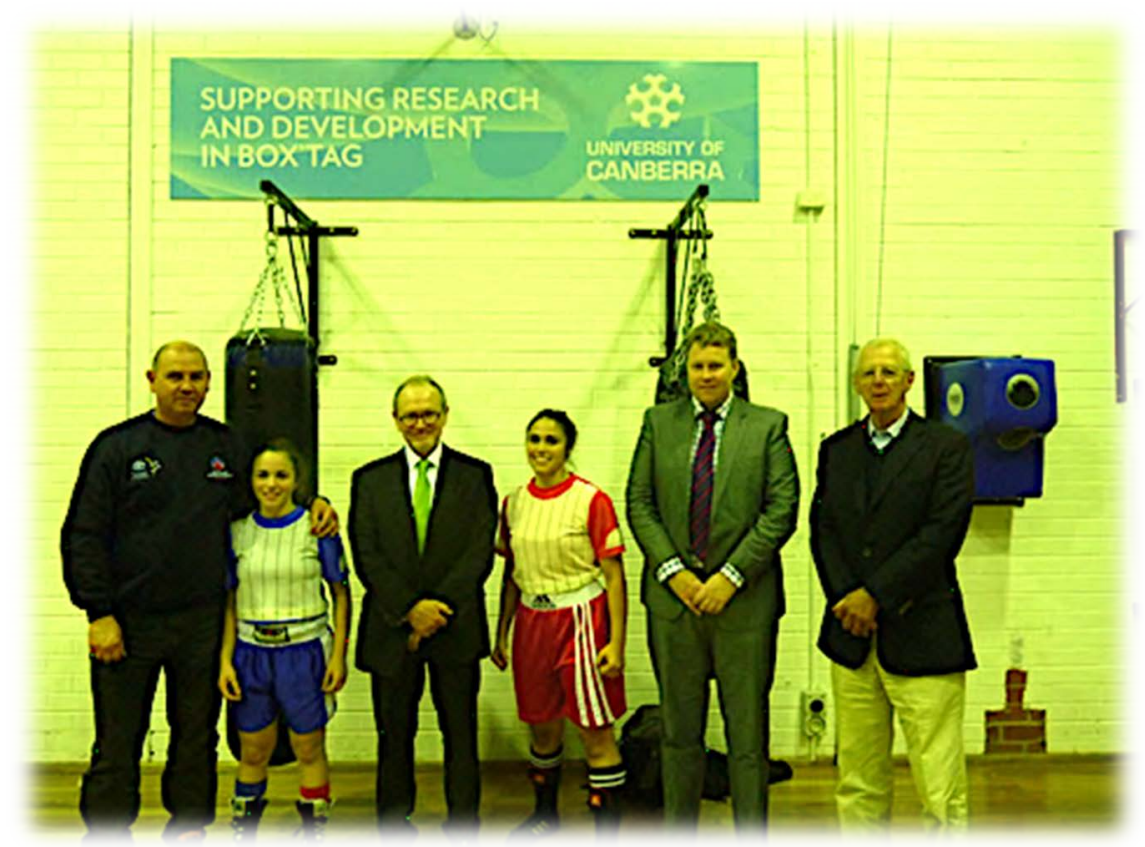

Figure 1. Photograph taken inside the Field R\&D centre, showing one of three prominent signs highlighting the partnership between the PCYC and the University of Canberra. Present in the photograph are Mr Bodo Andreass, then Head Coach of Boxing Australia, Professor Stephen Parker, then Vice-Chancellor of the University of Canberra, Mr Kable Kellaway, then CEO of Boxing Australia, Mr Jim Ferguson, former CEO of the Australian Sport Commission and a Boxing Australia Board Member, and two young female program participants.

Additionally, the involvement of the coach/researcher in university postgraduate studies necessitated the reading of extensive literature that enabled him to progressively contextualise and interpret the athlete feed back, and this too influenced the evolution of the program.

Key aspects of the evolution included a shift away from a focus on competition toward building a sense of community, greater use of constrained games for the teaching and learning of skills and the development of physical qualities, increased emphasis on fun, and adoption of more holistic approaches to athlete development. The notion of competition was replaced by fostering of cooperation between participants to prepare for "public performances" designed to display current competencies. Eventually, the program differed so much from the original Box'Tag concept that we decided to give it a new name-ModBox.

As the program advanced, some long-term participants quite naturally began to take on roles as informal mentors to other participants, and a few effectively became assistant coaches. This natural progression was actively encouraged. The informal mentors were all adults aged 28 - 60 years. The emergent assistant coaches included several young people in the age range of $14-20$ years. Their coaching activities were directed largely toward participants in their own age bracket or younger, but during some training sessions they served also as leaders for intergenerational training groups. 


\section{Previous Evaluation of Modified Boxing Program and Rationale for Present Study}

We have previously published several papers that provide evaluation of the program from specific perspectives [3] [4] [5]. Interviews with selected long-term program participants revealed that their commitment to the program could be explained largely by a perception of belonging to a special community, the existence of strong coach-athlete relationships, and a belief that the training was purposeful and placed high emphasis on safety [3]. Subsequently, thematic analysis of written surveys completed by 38 participants who had maintained regular involvement for at least three years showed that the most valued aspects of the program were that it offered a friendly, welcoming and supportive environment, was more than just a sport program in the sense that it entailed development of a cooperative community, incorporated a flexible and accommodating training schedule, and provided training that was safe, fun and beneficial in multiple respects [5].

In the process of examining the interview and survey data, we came across several suggestions that participation in the program was having positive influences on the lives of young participants. We therefore decided to undertake a study specifically aimed at determining whether this was the case. It seemed important to identify the nature of any positive effects on youth development and, insofar as possible, the specific program features responsible for those effects, since this could assist successful implementation of similar programs elsewhere. The further study is detailed below.

\section{Overview of Study Methods and Philosophical Assumptions}

To address the research questions as to whether the program became an instrument of positive youth development and how the program might have produced any such effect, we explored "insider data" collected by the lead author during the final two years of his almost 5 -year dual role as coach/researcher of the program. The analysis was confined to the final two years because it was during this period that the program reached peak maturity. Campbell [6] and DeLyser [7] have noted that insider data often generate high-quality research outcomes due to the researcher having a superior understanding of the culture under investigation, more natural interactions with participants, and greater relational affiliation with group members. In the present case, the lead author "lived and breathed" the entire experience encompassed by the analysis. He developed and maintained strong and meaningful relationships with many of the participants, thereby creating a sense of joint endeavour that favoured the willingness of both parties to candidly express their thoughts and share ideas. Importantly, a highly systematic and deliberate approach to the cyclical processes of planning, session delivery, collecting feed back and program evaluation was employed and comprehensively documented in the lead author's journal. Updated most nights and 
including all aspects of the program, the journal served as a vehicle for recording the lead author's experiences, impressions and ideas, documenting comments made by participants, summarising salient discussions with other parties, logging the results of specific trials and experiments and making methodological notes. Data for the present study were sourced from the journal. While the continuous compilation of the journal had been undertaken by the lead author alone, it reflected a highly collaborative process in which program participants were central. The present study was therefore framed by an epistemological constructivist understanding that the knowledge would be socially co-constructed and generated from various perspectives [8], and guided by an ontological point-of-view that there would be different versions of the reality [9] that when analysed would provide a rich and detailed understanding of the experience [10].

\subsection{Independence and Validity of Data Set}

As highlighted above, occupying the dual role of coach/researcher throughout the period of the Canberra PCYC modified boxing program provided the lead author with several advantages, including being present when new patterns of behaviour emerged, the occurrence of natural interactions with program participants and, perhaps most importantly, a feeling of shared venture with the participants. At the same time, however, the coach/researcher was clearly affecting the situation on which he was also gathering data. Consequently, the data were not entirely independent of researcher influence. To deal with this issue, the lead author sought to achieve high levels of reflexivity (i.e., awareness of the influence that the lead author's presence as a researcher was having on the participants and of the ways in which the experience was affecting the lead author as a researcher [11]). This reflexivity was pursued through repeated cycles of introspective self-analysis (see for example, Figure 2) that were used in an attempt to recognise the possible influences that the role of the lead author as coach/researcher was having on his relationship with the program participants, the social structure of the setting and the generation of data.

The aim was to understand and record the lead author's own evolving preconceptions, assumptions, attitudes and beliefs so that their effects on the research data could be considered. While the relationship that existed between the lead author and participants likely facilitated candour of discussions that would have been difficult for a detached researcher to accomplish, there was nevertheless potential for a power imbalance to occur during the post-training discussions [12] (resulting from the discussions being initiated by the program coach/researcher), affecting the validity of data recorded in the journal. This risk was minimised by:

- Prior development, over at least a two-year period, of mutual trust and rapport.

- Use of a relaxed, interactive and conversational approach to interviewing, and positioning of the interviews as a reciprocal information-sharing experience. 


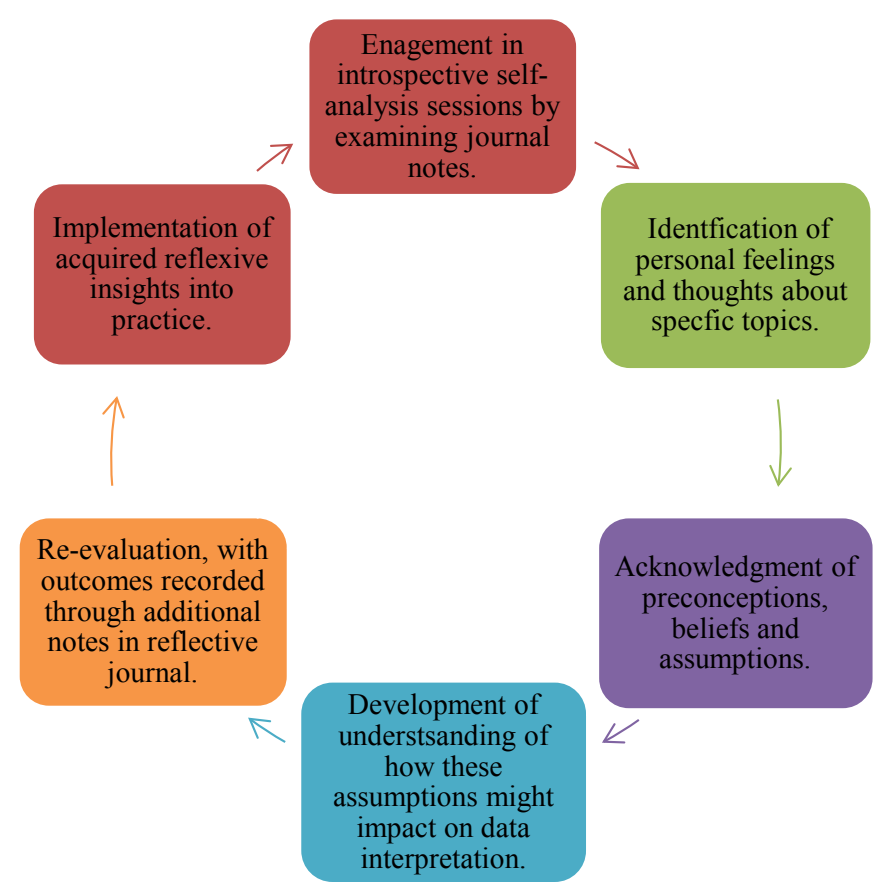

Figure 2. Overview of the introspective self-analysis process that was used by the lead author to constantly identify the influence that his presence as a coach/researcher of the program was having on the participants and research setting while also recognising how the experience was affecting him.

- Connectedness of both the participant and the coach/researcher to the work, creating a sense of collaboration that favoured the willingness of both parties to honestly express their thoughts.

In view of the above, we believe that the data recorded in the lead author's journal provided the truest possible representation of the opinions and experiences of the program participants.

\subsection{Ethical Clearance}

Ethical approval for this study was obtained from the University of Canberra Human Research Ethics Committee. When joining the modified boxing program all participants were informed that they were essentially joining a research and development project and were provided with sufficient information to ensure that they had an adequate understanding of the risks, benefits, purpose and nature of the research. Participants were also advised that they could elect to disengage with any of the research activities at any time and that this choice would not predispose them to prejudicial judgment and/or exclusion from the training environment. The purpose of providing such information and seeking consent was not merely a matter of satisfying a formal requirement. The aim was to develop a mutual understanding between the participants and ourselves [13].

\subsection{Research Sample}

We examined data from journal records of serial post-training discussions be- 
tween the coach/researcher and 16 program participants over the 2 -year period. The 16 participants were purposively selected based on the following criteria:

- They had at least two years of experience working with the lead author/researcher.

- They had self-reported that participation in the program was having positive effects on them, their family members and/or young people with whom they were interacting.

- They were considered capable of providing detailed responses and, as a group, giving rich and varied accounts of their experience.

Further information on the characteristics of the selected participants appears in Table 1. The sample included six young people aged $13-17$ years and 10 adults aged 20 - 60 years. Two of the young people were not only program

Table 1. Details of participants who shared rich and varied accounts of their experiences with the Canberra program during the two years of post-training discussions.

\begin{tabular}{|c|c|c|c|}
\hline Age and gender & Program attendance & Participation details & Discussion format \\
\hline 13 yr old $(M)$ & Twice per week & Athlete & $\begin{array}{l}\text { Participated in the individual } \\
\text { post-training discussions with his Father. }\end{array}$ \\
\hline 14 yr old $(F)$ & 3 times per week & Athlete & $\begin{array}{l}\text { Participated in the individual } \\
\text { post-training discussions with her Mother. }\end{array}$ \\
\hline 14 yr old $(\mathrm{F})$ & 4 times per week & Athlete/Junior coach & Participated in both formats. \\
\hline $15 \mathrm{yr}$ old $(\mathrm{M})$ & Twice per week & Athlete & $\begin{array}{l}\text { Participated in the individual } \\
\text { post-training discussions with his Father. }\end{array}$ \\
\hline 16 yr old $(F)$ & 4 times per week & Athlete/Junior coach & Participated in both formats. \\
\hline 17 yr old $(\mathrm{M})$ & Twice per week & Athlete & $\begin{array}{l}\text { Participated in the individual } \\
\text { post-training discussions with his Father. }\end{array}$ \\
\hline 20 yr old $(\mathrm{M})$ & 4 times per week & Athlete/Junior coach & Participated in both formats. \\
\hline 28 yr old $(\mathrm{M})$ & 3 times per week & Athlete/Informal mentor & Participated in both formats. \\
\hline 36 yr old $(F)$ & 3 times per week & Athlete/Informal mentor & Participated in both formats. \\
\hline 37 yr old $(F)$ & 3 times per week & Mother of female participant & $\begin{array}{l}\text { Participated in the individual post-training } \\
\text { discussions with and without her daughter being present. }\end{array}$ \\
\hline 43 yr old $(F)$ & 3 times per week & $\begin{array}{l}\text { Athlete and Mother of } 5 \text { female } \\
\text { participants }\end{array}$ & $\begin{array}{l}\text { Participated in both formats with and } \\
\text { without her daughters being present. }\end{array}$ \\
\hline 46 yr old $(M)$ & Twice per week & $\begin{array}{l}\text { Athlete and Father of } 1 \text { male } \\
\text { participant and } 1 \text { female participant }\end{array}$ & Participated in both formats without his children being present. \\
\hline 48 yr old $(\mathrm{F})$ & 3 times per week & Athlete/Informal mentor & Participated in both formats. \\
\hline 52 yr old $(M)$ & Twice per week & $\begin{array}{l}\text { Athlete and Father of } 1 \text { male } \\
\text { participant }\end{array}$ & $\begin{array}{l}\text { Participated in both formats with } \\
\text { and without his son being present. }\end{array}$ \\
\hline $55 \mathrm{yr}$ old $(\mathrm{M})$ & Twice per week & $\begin{array}{c}\text { Athlete and Father of } 1 \\
\text { male participant }\end{array}$ & Participated in both formats without his son being present. \\
\hline $60 \mathrm{yr}$ old $(\mathrm{M})$ & 3 times per week & Athlete/Informal mentor & Participated in the small group post-training discussions. \\
\hline $\begin{array}{l}\text { Age range } \\
(13-60 \mathrm{yrs})\end{array}$ & $\begin{array}{l}\text { Sessions per week } \\
\qquad \bar{x}=2.812\end{array}$ & $\begin{array}{l}\text { Gender breakdown } \\
9 \text { males, } 7 \text { females }\end{array}$ & $\begin{array}{l}\text { Individual sessions: } 5 \\
\text { Small groups only: } 1 \\
\text { Both formats: } 10\end{array}$ \\
\hline
\end{tabular}


participants but also had roles as assistant coaches of peers. All but one of the adults regularly took part in training sessions, with the sole exception being the mother of a female participant. Four of the other adults were also parents of young people included in the study, while four served as informal mentors for young program participants and one was an assistant coach. The inclusion in the study sample of people differing in age, gender and role within the modified boxing program ensured that diverse perspectives were obtained in the effort to answer the research questions.

The discussions with members of the study sample were held immediately after training sessions and occurred in two different formats. There were 42 individual conversations of $\sim 3-12$ min duration $(\bar{x}=\sim 7$ mins $)$ and 95 small group post-training talks of $\sim 25-50$ min duration $(\bar{x}=\sim 34$ mins). Overall, they produced a total of 259 journal entries, but only 137 or just over half (52.9\%) of these related directly to the research questions and were therefore considered suitable for further analysis (see for example, Table 2).

\subsection{Data Analysis}

Data generated from the individual and small group post-training discussions (as recorded in the lead author's journal) underwent a 6-phase iterative thematic analysis procedure consistent with the guidelines outlined by Braun \& Clarke [14] for the identification, coding, interpretation and reporting of themes existing within qualitative data sets. This process is illustrated in Figure 3 and described in detail in the subsequent text.

Table 2. Example of the formatting process used throughout the project for the organisation and storage of journal entries. An example of the funneling process used during the post-training discussions to enable participants to reflect on their initial response and offer a more detailed explanation can also be seen.

Date: Wednesday $16^{\text {th }}$ December 2015

Time: 19:30

Location: Administration area

Participant: Kim (pseudonym)

After short greetings and exchanges of pleasantries, discussions began with the coach/researcher asking an open-ended question. For example, in this entry the following question was asked: "Didn't Debbie (pseudonym for Kim's daughter) do well again tonight?"

Responses were then investigated further by use of a funneling technique outlined by Smith \& Osborn [15]. For instance, the initial response to the above question was: "She sure did. I am so proud of her right now, even some of her teachers have commented on how well she is doing." An open-ended probe was then used to "draw out" the meaning of this reply, "That must make you proud! What do think has contributed to the change in behaviour?" To which Kim answered, "I think coming here has a lot to do with it. There are so many good people here, and mixing with the likes of Jane and Sara (pseudonyms for two of the older female participant/informal mentors) has really influenced her behaviour and improved her outlook."

An open-ended prompt was used at this stage to further explore the previous response- "Really, in which way?" By this stage of the process a richer description of the original answer was usually provided, as can be seen from the following response from Kim: "Well, Jane and Sara are great role models and I think their positive attitude has rubbed off on Debbie." 


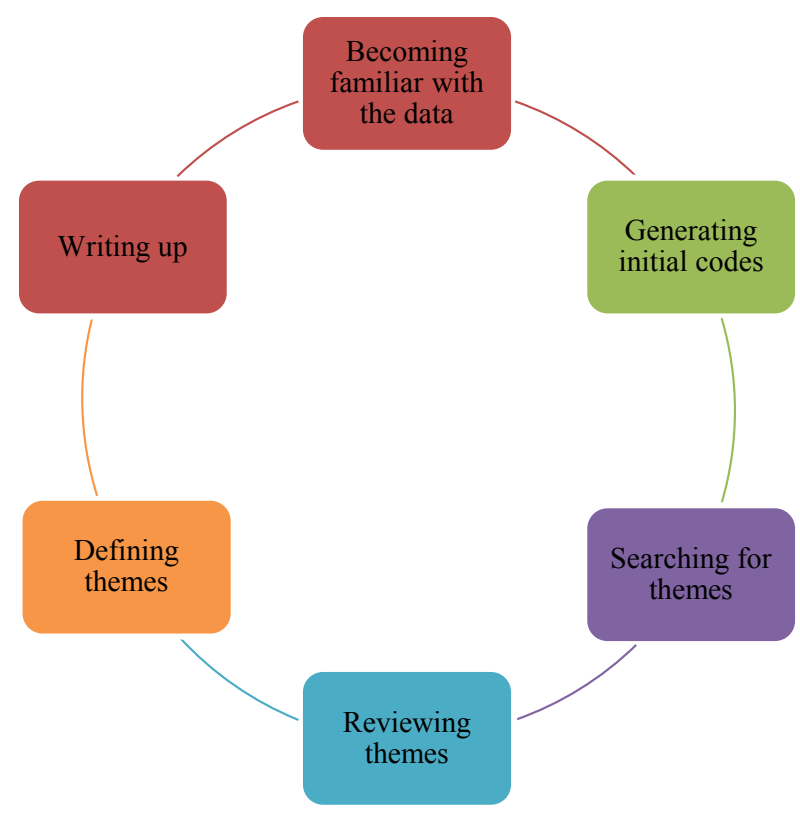

Figure 3. The iterative and reflective process by which data were analysed. Following this process provided a framework for the systematic review of the entire data set, created an opportunity for the interpretation of separate accounts, assisted with generation of initial codes and enabled development of integrated themes.

\subsubsection{Becoming Familiar with the Data}

Our aim during the first phase of the analysis was to become fully immersed in the data by re-familiarising ourselves with the journal entries and field notes. To assist this process, attention was initially given to the discussions between the coach/researcher and individual program participants, before shifting attention to the small informal focus groups. However, given the lead author's extensive background with the data, this task was inevitably undertaken with considerable prior knowledge and some pre-existing thoughts. Since the prior knowledge and thoughts were previously explored and documented during the data collection phase through the lead author's introspective self-analysis sessions, that phase could be considered as the true beginning of the analysis process, in accordance with the insights of Tuckett [16]. In keeping with experience reported by Nowell et al. [17], recognition of this chronology meant that the whole analysis was much more iterative and reflective than might otherwise have been the case. Nevertheless, repeated readings of the data including the lead author's notes from the self-analysis sessions ensured we were thoroughly engaged with the data during the early stages of the analysis undertaken specifically for the preparation of this paper. Our engagement with the data was aided further by use of an additional procedure that involved watching and re-watching two short videos created by some of the Canberra PCYC modified boxing program participants to demonstrate what the program meant to them [18] [19]. Repeated viewing of the video footage not only facilitated our re-connection with the data, but also assisted with the subsequent development of the various codes and 
themes by highlighting aspects of the program that participants considered were of most value. Readers are encouraged to adopt the same approach when reviewing this paper by using the hyperlinks contained within the reference section to view the relevant footage.

\subsubsection{Generating Initial Codes}

Attention was given to the specific characteristics of the data during this phase. We worked through the entire data set line-by-line to ensure that any passage, sentence or word that seemed relevant to the research questions was saved for further scrutiny through a process known as inductive coding. According to Braun \& Clarke [14], the primary purpose of an inductive analysis is to allow research findings to emerge from the themes inherent in the data. This approach differs from the more theory-driven deductive analysis where code and theme development are directed by existing concepts and ideas [14]. In our case, journal entries were inductively coded and recorded in two separate logs along with our initial thoughts and impressions, with one log relating to perceived effects of the program on aspects of youth development and the other to specific program features contributing to the effects.

\subsubsection{Searching for Themes}

This phase of the analysis was performed for each log and involved grouping all the potentially relevant coded passages and extracts into initial themes based on their overall pertinence to the associated research question. For example, in the case of the log pertaining to program effects, two original codes related to perceptions of improved confidence and higher levels of motivation were subsequently organised into an initial theme titled: "Conditions supportive of psychological developmental outcomes". Importantly, by the end of this phase codes that appeared to be most germane to the research question had been organised into meaningful themes, as can be seen from the example in Table 3.

\subsubsection{Reviewing the Themes}

During this phase we explored and assessed the overall quality of each theme to ensure that it accurately reflected what was evident in the data and that when themes were connected, they would provide a rich and detailed account of the experience. For example, during our review the code titled "higher levels of motivation" was considered unnecessary since it was much more of a stand-alone factor contributing to the development of outcomes rather than an underpinning code. It was therefore repositioned and subsequently used as a subtheme to support the presented findings. Our review also revealed that the theme titled "Conditions supportive of psychological developmental outcomes" was too broad and required refinement to provide greater resolution. In the end, it was decided to merge this theme (and the associated coded extracts and initial thoughts) with one titled "Positive and supportive relationships" to ensure that the data could be presented in the most meaningful, logical and accurate way. 
Table 3. An example of how preliminary themes were developed from the initial codes and underpinning initial impressions.

\begin{tabular}{|c|c|}
\hline \multicolumn{2}{|c|}{ Initial Theme: Conditions supportive of psychological developmental outcomes } \\
\hline \multicolumn{2}{|c|}{ Codes } \\
\hline Improved confidence & Higher levels of motivation \\
\hline \multicolumn{2}{|c|}{ Initial impressions } \\
\hline Positive influences & Meaningful interactions \\
\hline Constant encouragement & High levels of autonomy \\
\hline Focus on improvement and having fun & Developing skills/progressing \\
\hline \multicolumn{2}{|c|}{ Extracts from journal entries } \\
\hline $\begin{array}{l}\text { Training with Mick (pseudonym) is awesome. } \\
\text { He has taught me how to believe in myself } \\
\text { and that I can do anything I set my mind to. }\end{array}$ & $\begin{array}{l}\text { I've learned lots of new skills since } \\
\text { being here, and not just sporting ones. }\end{array}$ \\
\hline $\begin{array}{l}\text { I think some of it has do with the } \\
\text { amount of encouragement he is getting. }\end{array}$ & $\begin{array}{l}\text { I know John (pseudonym) really likes the fact } \\
\text { that he gets to have a say about how to do } \\
\text { things and appreciates the praise he gets. }\end{array}$ \\
\hline $\begin{array}{l}\text { Debbie (pseudonym) said that the best thing } \\
\text { about the program is that it's focused on } \\
\text { improving and being the best you can be. }\end{array}$ & $\begin{array}{l}\text { Everyone is really positive and always } \\
\text { congratulating each other. }\end{array}$ \\
\hline
\end{tabular}

\subsubsection{Defining Themes}

In this phase, consideration was given to the naming of each theme so that an immediate indication of its essence could be clearly conveyed to the reader. Determination of the names was assisted by informal discussions (peer-debriefing) between us and colleagues.

\subsubsection{Writing Up}

During the write-up phase we followed the advice of King [20] and Aronson [21] by combining relevant literature with specially selected words, extracts and comments from the original journal entries to help illustrate and exemplify elements of each theme and to demonstrate practical interpretations of existing theories.

\section{Results}

The analysis process outlined above revealed three predominant themes relating to positive developmental outcomes and three themes that provide an indication of program characteristics that facilitated these outcomes. These themes are presented in Table 4 and explained in detail in the subsequent text. It should be noted that comments attributed to participants are drawn from field notes recorded by the first author and indicate his recollections of what was said rather than being verbatim quotes. Nevertheless, because the notes were recorded as soon as possible (generally $1-2$ hours) after each discussion, they provide an authentic representation of the comments. All names included in presented comments and extracts are pseudonyms. 
Table 4. Summary of perceived positive effects of participation in the Canberra PCYC Modified Boxing Program and the program characteristics contributing to them.

Perceived developmental outcomes
Higher levels of determination
Increased self-confidence
Leadership development
Program characteristics apparently facilitating perceived outcomes
Positive and supportive relationships
The collaborative nature of the program
Opportunities for observational learning

\subsection{Perceived Developmental Outcomes}

There was a strong consensus within the study sample that participation in the Canberra PCYC modified boxing program provided young people with opportunities that assisted their development of such important character traits as determination, confidence and leadership skills. For example, 12 of the 16 members of the study sample ( 7 males and 5 females across all age groups) reported that they had either developed or observed the development of higher levels of determination during their time with the program. Importantly, all six of the younger sample members (13 - 17 yrs old) believed that their involvement with the program taught them the importance of persevering when facing challenges in other areas of life, as can be seen from the following examples: "Training here has made me a better student. I'm able to get through the hard times at school much better now and have learnt you have to stick with things to get results"-(Female participant, 14 yrs old). "I know I'm a lot stronger and much more determined now, and I've been putting these [qualities] to great use at basketball”-(Male participant, 17 yrs old). "I've learnt that if you want something worth while, you have to be prepared to work hard and never quit. I'm applying the same mentality to my studies and getting heaps better results"-(Male participant, 15 yrs old).

For two of the father/participants and one of the mother/participants watching their sons and daughters display high levels of determination at intensive physical training sessions was "the best thing", "great to watch" and a "real highlight" of their experiences. These sample members saw the completion of such sessions as contributing not only to the development of certain physical qualities, but also to the learning of "skills" required for present and future success. For instance, during an individual post-training discussion, one of the father/participants said "Being a part of this program has changed the way Gary approaches life. Prior to training here he was quite shy and would give up if things got a bit hard. Not now, though. He is much more focused and determined these days and really enjoys challenging himself"-(Male participant, 52 yrs old). 
A similar view was shared by one of the mother/participants when she noted the following during an individual post-training discussion: "Training beside my daughters and watching them grow into strong, independent, respectful and determined young women has been a real highlight for me. These traits are so important and will definitely help them in the future"-(Female participant, 43 yrs old).

When recounting how he thought participation in the program was affecting his son, one father/participant said "One of the most important things you've taught John is to never give up, no matter how hard it gets. I'm certain the lessons he's learning here will help him later in life"-(Male participant, 55 yrs old).

Development of youth leadership skills was another important outcome attributed to participation in the program. The emergence of this theme suggests that the program was successful at achieving one of the primary goals of the Canberra PCYC-diverting young people from risk of negative involvement with the criminal justice system by providing opportunities for them to develop not only sporting skills but also critical life skills. The perception that participation in the program assisted with the development of leadership skills is clearly demonstrated in the following extracts: "I can't believe how much Gary has changed since coming here. He is turning into a great little leader"-(Male participant, 52 yrs old). "In the beginning I was just looking for an activity that me and the kids could do together. I had no idea it would end up being so positive and beneficial for us, especially for Dave. He's much more assertive than he used to be and has even started helping out around home to make sure we get here on time"-(Male participant, 46 yrs old). "I've noticed a big difference in the way the girls do things these days. They're much more proactive and considerate"-(Female participant, 43 yrs old). "I've learnt that a good leader is kind to other people and always tries to help"-(Male participant, 13 yrs old).

Participation in the program was also linked to perceptions of improved self-confidence, with most members of the study sample making some mention of it during the post-training discussions (13 respondents, across all age groups). For the six younger sample members (13 - 17 yrs old), the concept of self-confidence was associated with an ability to complete physically challenging training sessions, surpass previous best efforts and successfully execute newly acquired skills. This was particularly true for one of the younger female participants, who said "I'm much more confident than I used to be and I'm nowhere near as timid as I was"-(Female participant, 14 yrs old). These views were shared by her mother, who added "That's for sure! I've noticed a big change in you over the past 6 months. You' re certainly are a lot more confident these days, especially down here"-(Female participant, 37 yrs old). When asked why she thought she was feeling more confident, the young person said, "I think some of it's got to do with the training sessions. They' re always challenging so completing them always feels good. It's like, yes! I did it! You reinforce this at the end of sessions by making us do the run throughs and high-fives-that's like an ac- 
knowledgement that we've done our best. But I think it's also because everyone is so encouraging and no-one judges you. That just makes you more confident and you just start to believe in yourself'-(Female participant, 14 yrs old). One of the younger male participants, who also assisted as a junior coach with the program, described how he felt more confident when he said "I believe I have the skills to be not only a successful athlete, but also an effective coach. I'm much more confident in my abilities these days and know that I will accomplish these goals with your help"-(Male participant/junior coach, $20 \mathrm{yrs}$ old).

According to two of the father/participants, the concept of self-confidence was somewhat domain-specific, and not necessarily transferable to other places or settings, as evident from the following comments: "I just wish Dave was as confident at footy as he is here, he'd be a super star"-(Male participant, 46 yrs old). "I know what you mean mate, it's the same with John. Down here, he is smashing it but for whatever reason he's still not very confident at school and we' re still having some issues with bullying"-(Male participant, 55 yrs old). One of the informal mentors, who in addition to being a program participant was also a long-term mixed martial-arts coach, shared a similar experience when he said "Confidence is a really interesting thing. I've seen and worked with a lot of kids who are great at sport and appear to be super confident but suffer when they do something they' re not used to doing. We had one young person who was an exceptional mixed martial artist and could do anything on the mats. He was always confident at training but when we invited him to give a talk to some kids at a local school he froze and couldn't even get through the first sentence. Luckily, the sensei was there and finished the session without too much fuss'. Later in the discussion the informal mentor went on to explain what he believed were some of the challenges associated with the development of self-confidence, when he added "I think the majority of young people who become confident adults do so because they've been fortunate enough to grow up in loving and supportive environments. Some of the kids that we work with, however, haven't been as fortunate and have had to deal with a lot of negative experiences. This really affects their ability to become happy, well-adjusted and confident adults"-(Male participant/informal mentor, $60 \mathrm{yrs}$ old).

\subsection{Program Characteristics Apparently Facilitating Perceived Outcomes}

Throughout the analysis an attempt was made to gain an understanding of ways in which the identified developmental outcomes were achieved. The first theme to emerge from this area of focus was that the program environment fostered establishment of positive and supportive relationships. This theme was underpinned by a number of overlapping descriptions and comments. For example, when describing the coach-athlete relationship participants used words such as positive, supportive and caring to express their thoughts and then reused the same words to define the other relationships developed during their time with the program. This was especially true for the youngest male participant who ex- 
plained how important the relationships were for his development, when he said "They're [the relationships] probably the most important thing about the program. Everybody's really positive and supportive here and we all look out for each other. We all know how much you care about us and it's the same with the other guys [informal mentors]. Having that support and knowing people care about you makes you want to become a better person"-(Male participant, 13 yrs old). The young person's father added to the discussion, when he said " $I$ agree. Knowing everyone wants the best for Gary is one of the main reasons why we both love coming here"-(Male participant, 52 yrs old). Similar accounts were provided by one of the junior coach/participants during a post-training discussion also attended by her mother, when she noted: "One of the main differences with our program is the strength of the relationships. I know if I have a problem I can talk to you, Jane, Sara or one my friends about it and there won't be any judgement. Having that type of support makes a really big difference"-(Female participant/junior coach, 16 yrs old). Her mother added “What about me? Don't you think you can talk to me? Only joking Bella. I think it's great that you have so many good friends here and feel confident talking to them about personal stuff. There's nothing better or more important than good friends"-(Female participant, 43 yrs old).

Supporting the development of young people through the provision of positive and supportive relationships was seen by some of the program's older informal mentors ( 2 males and 2 females, aged 28 - 60 yrs old) as a vital component of the modified boxing program, as evident from the following examples: "There's no need to thank me [for the mentoring role]. I do it because I want to help the younger guys. I mean, what we do here is not just about playing sport, it's also about becoming a better person and helping others, right?"-(Female participant/informal mentor, 36 yrs old). "I know what it's like to feel isolated and to have to struggle alone. That's why I'm so committed to helping out down here"-(Male participant/informal mentor, 28 yrs old). "I think the informal mentoring model has been really successful and I'm trying to implement something similar at my [martial arts] program"-(Male participant/informal mentor, 60 yrs old).

In addition to the above, our analysis revealed that the collaborative nature of the program (i.e., the involvement of the participants in determining program content and directions) was likely instrumental in achievement of the developmental outcomes. For instance, all 6 of the younger participants considered that the collaboration had contributed to their higher levels of self-confidence and development of leadership skills, and used the following phrases to express their feelings "It's empowering", "I always feel like I'm contributing to the program", "I know my opinions matter" and "I always feel valued and important". The collaborative approach to session planning and delivery resulted in a majority of participants seeing themselves as co-developers of the program which in turn increased opportunities for acquisition of new knowledge, attitudes and beliefs, as is evident from the following extracts: "The way we do things is different to 
how things are done at basketball. We're much more of a team here and everyone is considered important. It's not that I don't feel important at basketball, it's just that I go there knowing I'm there to either train or play and that the coach will make all the decisions and I'm just expected to follow them without any input or involvement. It's not like that here, you' re always seeking feed back from us, and the really cool thing is that everyone's free to say what we liked and didn't like about a session. Our suggestions are nearly always implemented and everyone works together to keep making the program better"-(Male participant, 17 yrs old). "Being referred to as a co-contributor to the program and being told that your opinion matters confirms that you think highly of us. This changed the way me and the kids thought about our participation. We've come to realise that what we're doing here is really important and that we're not just participants, we' re part of the team and we' re helping to build something really unique and special"-(Male participant, 46 yrs old). "I definitely think the environment at our club promotes cooperation and brings people together. It's unique in that way and nothing like the other clubs I've been involved with. We work together here and everyone is treated equally, regardless of their age, gender, or level of experience. This approach has helped me become a better leader and a more effective coach. I know it's the same for the younger guys, you can see how far they've come. We're really proud of what we're doing here"-(Male participant/informal mentor, 60 yrs old).

The final theme to emerge from our analysis highlights the important role that observational learning played in the development and facilitation of positive and transformative sporting experiences. According to Bandura [22], this more informal and self-regulative approach to learning explains how individuals are able to learn and develop new behaviours through the observation of others and the interpretation of their actions. The importance of observational learning in the present context was clearly demonstrated by one of the younger female participants, when she said "Training here has taught me how to get along with people who aren't part of my family and how to see things from other people's perspectives. It's also taught me what real leadership is and the importance of helping others". When asked how she learnt these things the young person said, "By watching you and some of the other guys [informal mentors]"-(Female participant, 14 yrs old).

A similar account was provided by one of the other female participants, who suggested that the structure of the program supported and promoted social learning, when she said "The way the program is structured and delivered means everyone learns from each other". When asked if she could elaborate on this, she said "I know I've learnt heaps just from watching how you do things, but I'm also learning by watching and talking to some of the other guys [informal mentors]"-(Female participant/junior coach, 16 yrs old).

The importance of observational learning was also noted by some of the older parent/participants, with 2 fathers and 1 mother mentioning it several times during the individual post-training discussions. For these three older partici- 
pants, this form of learning was seen as a long-term and continuous process that depended on prolonged exposure to positive role models and high levels of positive reinforcement, as summarised by one of the father participants, when he said "Just look at the progress Gary has made since joining the program. Everybody knows and comments that he is much more confident and motivated these days. He loves coming down here and calls it his home-away-from-home. He reckons it's the best thing he's ever done. And you know what? I reckon it's because of Mick. Gary idolises him and has a lot of respect for what he achieved in boxing and the way in which he overcame his personal challenges". When asked if he could give an example of how these interactions were positively influencing his son's behaviour, the father participant said "Mick not only demonstrates the type of behaviour that's required to be successful in sport, he's also demonstrating what's required to succeed at life. It's more than that though, it's all the little things he does. He's always challenging and encouraging Gary to do his best and always acknowledges his efforts. I reckon this is the main reason why Gary likes training here so often. For me, this is really good because I know there's a lot of good people for him to learn from down here"-(Male participant, 52 yrs old).

Observational learning appears to have played an important part in helping the young people to develop their leadership skills. For example, at one of the individual post-training discussions a participant/junior coach said "I'm definitely not as shy as I used to be and I do things now that I wouldn't have done before. So I'd say that I've definitely matured as a person and have become a better leader from coaching the younger kids and from watching you coach". When asked how observing the lead author while coaching was helping her in her role as a junior coach, the young person said "It's not just watching you, it's also coaching with you. You just sort of learn as you go and keep getting better. I think I'm much better at interacting with the kids now and also better at planning and running a session. I know I've still got a lot to learn but I also know that I'll keep getting better" - (Female participant/junior coach, 16 yrs old). A similar response was provided by another athlete/junior coach, when she said "Working with you has helped me become more confident and a much better leader". When asked if she could elaborate on her response, the young person when on to say "Well, I wasn't much of a leader before and used to just copy what everyone else was doing. It's not that I didn't want to coach, it's just that I didn't know what to do and didn't believe in myself. I just followed everybody around and did what they were doing. I think I'm much more confident now, and as a result I'm also a much better coach". When asked how she thought she developed these skills, the young person said "I think it's a combination of things. I've definitely learnt from watching you and by getting in and doing it, but I've also learnt a lot from our chats-they've been really helpfur'-(Female participant/junior coach, 14 yrs old).

\section{Discussion}

The findings of this study suggest that the Canberra PCYC modified boxing 
program had positive effects on the broader development of participating youth, particularly by increasing their determination, self-confidence and leadership skills. Among program characteristics contributing to these outcomes, the fostering of positive and supportive relationships, collaborative involvement of the young people in determining program directions and provision of opportunities for positive observational learning appear to have been predominant.

In the following pages, we review a range of literature concerning the concept of positive youth development, conditions necessary for it to occur, the ability of sport programs to accomplish it, and theoretical models of the processes through which it occurs. We then turn our attention to relationships between that literature and the characteristics of the Canberra PCYC modified boxing program, thereby contextualising our findings.

\subsection{What Is Meant by "Positive Youth Development"?}

The concept of positive youth development has its roots in the positive psychology movement which emphasises the need to understand the psychological requirements for humans to flourish and reach their full potential, as opposed to a focus only on mental health issues [23]. The positive psychology movement has gained considerable momentum over the past 20 years [24], although the ideas underpinning it can be traced back to ancient times [25].

Essentially, positive youth development entails enabling adolescents to thrive and build skills necessary to a fulfilling and productive adulthood [26] [27]. It has been formally defined as "an intentional, pro-social approach that engages youth within their communities, schools, organizations, peer groups, and families in a manner that is productive and constructive, recognizes, utilizes, and enhances young people's strengths, and promotes positive outcomes for young people by providing opportunities, fostering positive relationships, and furnishing the support needed to build on their leadership strengths" [27].

Catalano et al. [28] note that before the 1970s many youth programs in the United States were interventionist in nature, catering for young people who were in crisis situations, and aimed at reducing juvenile crime rates and correcting character deficiencies. As limitations of this approach became evident, there was a shift toward programs aimed at prevention (rather than just rectification) of problem behaviours. The intention was to divert at-risk youth from situations that could otherwise lead them to criminality and/or other anti-social activities. It was subsequently realised, however, that absence of major problems during adolescence is not equivalent to adolescent flourishing, and that programs must be directed also toward building of valuable life skills. The contemporary phase in which youth programs seek to promote positive youth development was therefore initiated.

Advocates of positive youth development regard the characteristics of youth as resources to be developed, rather than as problems to be solved [29]. Catalano et al. [28] contend that positive youth programs necessarily incorporate at least 
one of 16 basic objectives or "constructs", with these identified as recognition for positive behaviour, provision of opportunities for pro-social involvement and the fostering of bonding, resilience, social competence, emotional competence, cognitive competence, behavioural competence, moral competence, self-determination, spirituality, self-efficacy, clear and positive identity, belief in the future and pro-social norms.

\subsection{A General Model of Positive Youth Development}

An influential framework for understanding the process of positive youth development is provided by the bioecological theory of human development conceived and progressively refined by Bronfenbrenner and colleagues from the late 1970s until 2005 [30]-[35] and subsequently summarised by Tudge et al. [36]. This theory holds that human development and behaviours are shaped by person-environment interactions that are influenced by four factors-process, person, context and time. The interaction process can be classified as either proximal or distal. Proximal processes are the personal, complex and reciprocal interactions that occur between a young person and the people, objects and symbols in their immediate surroundings on a regular basis over extended periods of time. They are believed to be the primary mechanism for development of competencies, values, beliefs and well-being [33] [35]. By exclusion, distal processes can be defined as bi-directional interactions more removed from the immediate environment of the young person, less regular and/or sustained for a relatively short time period. Occasional exposure to people of different cultural backgrounds, ethnicity, religious beliefs and/or social status may be considered an example [33] [35]. Distal processes are thought to have only an indirect and relatively small influence on youth development.

The bioecological theory recognises that the outcomes of interactions between person and environment are also influenced by the characteristics of the person. Biological and genetic characteristics are seen as important [32], along with demand, resource and force characteristics. Demand characteristics include, for instance, age, gender and physical appearance. Resource characteristics include intelligence, past experiences, skills, educational background, socio-economic status and level of parental care. Force characteristics relate to temperament, motivation and willingness to persevere [36].

The context of person-environment interactions is identified as another major determinant of outcomes [31]. Context can be divided into four categories. The first of these is known as the microsystem and incorporates the situations in which the young person is most directly and continually engaged, such as home, school, work, neighbourhood, religious institutions, friendship groups and sporting or other clubs. It is where proximal interactive processes are most likely to occur. The second context is termed the mesosystem and consists of linkages between elements of the microsystem. A further step removed from the young person is the exosystem, which is comprised of contexts in which the young 
person has no direct involvement, but which may nevertheless impact on development by affecting characteristics of the microsystem and/or mesosystem. An example would be a stressful parental work situation that affects the quality of the relationship between the parent and the developing young person. The final dimension of context is the macrosystem, which encompasses cultural setting, social norms, governmental structure and financial circumstances of the society in which the young person lives [36].

According to the bioecological theory, the human developmental outcomes of person-environment interactions are also influenced by time [34]. The theory differentiates between micro-time, meso-time and macro-time, but the underlying principle is that time can change circumstances in the short, medium and long terms, through effects on processes, individuals and contexts.

The notion that youth development is determined by person-environment interactions is central also to another prominent theory of youth development-the relational development assets theory described by Lerner et al. [37]. This theory proposes that when the inherent strengths (internal assets) of young people align with accessible environmental (external) assets favouring reinforcement of those strengths, positive youth development occurs. Environmental assets contributing to positive youth development may include individuals (within family, school or community settings), institutions (such as schools, churches, sporting clubs and community organisations) and opportunities for youth-adult collaboration.

\subsection{What Are the Outcomes of Positive Youth Development?}

In a recent scoping review of positive youth development programs of seven different types, Waid and Uhrich [38] documented a wide range of reported outcomes, including increases in self-esteem, self-concept, social and emotional skills, leadership skills, independence, sense of belonging, optimism, academic performance, problem-solving skills and creative expression, as well as decreases in aggression, substance abuse and risky sexual behaviours. Lerner et al. [39] argue, however, that positive youth development can be observed and quantified in terms of five key elements-confidence, competence, character, connection and caring. These elements are commonly known as the "Five Cs of positive youth development". Lerner et al. [39] posit that they lead naturally to a sixth C, contribution, as manifestation of a desire to assist maintenance and augmentation of the developmental assets that have enabled thriving. Conversely, the theory indicates that when youth lack access to appropriate developmental assets, their inherent strengths may fail to emerge, leading to low levels of the Five Cs and a high risk of psychological problems and anti-social behaviours.

The theory of Lerner et al. [39] has been subjected to multiple evaluations, some of which have demonstrated that relationships inferred by the theory are more complex than originally envisaged. For example, the original theory inferred that increasing levels of the Five Cs should be associated with reduction in problematic behaviours, but a subsequent study [40] revealed that changes in the 
two variables could be temporally offset, suggesting that if there is any causative link it might sometimes be latent. Additionally, it has been shown that effects of engagement in out-of-school activities on positive youth development vary as a function of neighbourhood characteristics, being greater in neighbourhoods with limited resources [41]. At the same time, though, many of the basic constructs of the theory have gained empirical support, highlighting the value of the theory in providing a framework for integrating and assessing the many potential effects of positive youth development.

Coakley [42] has pointed out that viewing the outcomes of positive youth development programs only in terms of changes in the characteristics of individual participants is reflective of a neo-liberal philosophical perspective, and that an effective program should also yield benefits to the whole community. Where programs cater for disadvantaged youth, such benefits may include increased ability of the group to discern and collectively address the sources of the disadvantage. In any case, increased socio-political awareness and civic engagement of youth should be regarded as desirable outcomes [43].

\subsection{What Are the Defining Features of Programs That Succeed in Positive Youth Development?}

Analysis of 25 positive youth development programs that met stringent criteria for effectiveness allowed Catalano et al. [28] to identify several common themes. All the programs addressed at least five of the 16 positive youth development constructs (see Section 7.1 above), and three specific constructs-fostering of competence, self-efficacy and pro-social norms-were universal. Twenty of the programs were delivered over a period of nine months or longer, 24 incorporated a structured curriculum or program of activities, and 24 gave consistent attention to quality assurance. Other important characteristics were clear communication of required standards for youth behaviour and affordance of opportunities for healthy bonding with adults, peers and younger children.

In 2002, a Committee on Community-Level Programs for Youth was established in the United States and charged with reviewing and integrating available data on programs aimed at positive youth development [44]. The Committee, which consisted of 20 people and included many leading academics in the youth development field, collated not only qualitative and research data but also reports from practitioners. This led to identification of eight key characteristics of the settings associated with successful youth development programs. The characteristics were physical and psychological safety (including low risk of confrontational interactions), appropriate structure (clear and consistent rules, firm control, continuity, predictability), supportive relationships (warmth, connectedness, secure attachments, good communication, responsiveness, guidance), promotion of a sense of belonging (social engagement, opportunities for formation of socio-cultural identity, meaningful inclusion regardless of gender, ethnicity, sexual orientation or disability), positive social norms (expectation of pro-social behaviours, clarity of obligations, modelling of values and morals), 
support for efficacy and mattering (taking youth seriously, empowering youth in ways that support autonomy, encouraging youth to make a real difference in their community, provision of meaningful challenge, quest for improvement rather than focus on current performance level), opportunities for building skills and socio-cultural capital (intentional exposure of youth to learning experiences aimed at enhancing physical, intellectual, social and emotional skills and building cultural literacy), and integration of family, school and community efforts.

According to Lerner et al. [37], the "Big 3" attributes of programs that effectively foster positive youth development are establishment of positive and sustained youth-adult relations, provision of opportunities for building life skills, and engagement of youth in valued family, school and community activities that afford them opportunities to take on leadership roles.

\subsection{Is Sport a Natural Vehicle for Positive Youth Development?}

In recent times it has become widely accepted that participation in sport and other structured recreational activities can assist with the positive growth and development of young people [45]-[50]. For example, it has been reported that young people who participate in sport display higher levels of self-esteem, self-confidence, problem-solving ability [51] [52] and critical life skills (the physical, behavioural and cognitive skills required to cope with the challenges of everyday life [53] [54]) than their non-sporting counterparts. In addition, youth sport participation has been linked to improved academic achievement and a lower likelihood of school dropout [55] [56], and is associated with such positive health behaviours as improved body weight management [57], healthy eating habits [58] and abstention from cigarette smoking [59].

Youth sport is also an excellent vehicle for the development of physical qualities [60] [61] [62] including coordination [63], muscle endurance [64], muscular strength [65] [66], flexibility and aerobic capacity [66] [67]. It can assist with the progressive refinement of fundamental movement and physical literacy skills - key requirements for sustained sport participation [68] [69] — and can aid development of positive physical activity habits thereby reducing the risk of diseases associated with sedentary lifestyle [70] [71].

On the other hand, youth sport can sometimes produce negative outcomes such as use of performance-enhancing drugs, engagement in anti-social behaviour [71] [72], excessive alcohol intake [72] [73], acts of violence and aggression [74] [75], and increased occurrence of injury [28] [76] [77]. From a developmental perspective, negative feelings such as low levels of self-confidence and self-esteem associated with perceptions of poor sporting ability are common in some youth sport settings [78] [79] and contribute to high adolescent dropout rates [80] [81].

Early sport specialization (i.e., early focus on one sport with a view to eventual attainment of elite status) is of particular concern, having been linked to athlete burnout, increased rates of overuse injuries, negative interactions with peers and 
family members, heightened levels of anxiety, low motivation, reduced social development and feelings of guilt following unsatisfactory performance [82] [83]. Despite these risks and numerous studies showing that sport performance at an early age is an unreliable predictor for future high-performance sport results, many parents, coaches, sport administrators and managers actively encourage and promote the practice [83] [84]. Since only $2 \%$ of young athletes will ever reach the highest levels of sport achievement [84] [85] the practice of exposing children and adolescents to highly-structured, year-round training and competition schedules with limited rest might sometimes be counterproductive in terms of attaining high-performance objectives and even more so in regard to holistic and positive youth development [42] [46] [86] [87].

Given that youth sport participation has potential to yield both positive and negative developmental outcomes, a question arises as to whether a quest for elite sport performance is worth the risk of negatively impacting on the personal growth and development of young people.

In direct contrast to the early specialization concept, some scholars have proposed an early diversification model that involves sampling of multiple sports and includes extensive exposure to deliberate play [84] [88] [89] [90] [91] [92]. The type of deliberate play advocated entails relatively flexible, unstructured approaches to skill development, designed to maximise fun and enjoyment, while creating opportunities for the acquisition of sport skills through participant experimentation and exploration [88] [89]. This approach is distinct from more structured deliberate practice methods that require focused attention on improving specific areas of performance and involve intentional engagement in repetitious skill-based learning activities designed solely for the development of expertise [84] [90] [91] [92] [93].

By delaying specialization until an age where young athletes are physiologically and psychologically mature enough to cope with the demands of increased training loads and the pressures of competition, the early diversification approach offers a significant advantage in regard to youth development. For instance, exposing young athletes to different training environments and experiences can prolong their engagement with sport, thereby providing the time required not only for the development of sporting skills but also for the achievement of broader social skills [94]. It is argued that under these conditions young athletes can still go on to achieve high-performance sporting success, but with this accomplished through careful planning and long-term periodization that accounts for the individual physical, social, and psychological development of each athlete [46] [88] [89] [93].

While the above suggests that young athletes can progress from novice to elite sport performers while minimising negative consequences associated with early specialization, it does not provide an adequate framework for the use of sport as a vehicle to assist with the positive growth and development of young people (see, for example, Figure 4). According to Sport for Development scholars, realisation of the latter outcome requires a specific approach to program 


\section{Sport Plus}

Promoting and developing the sport is the primary focus of a program. Attempting to assist with broader social issues is a secondary concern [95].
Plus Sport

The development of the social outcomes, and not the sport itself, is the central focus of a program[95].

Figure 4. A continuum for the development of positive social outcomes through sport. At one end of the spectrum the primary focus is the development of the sport, coaches, and athlete pathways, while social outcomes are considered secondary outcomes (Sport Plus). At the other end sport is used as a tool to attract participants, but then the main objective of the program is not sport-based (Plus Sport) [95].

design, implementation and delivery that actively incorporates appropriate role modelling and provides opportunities for attainment of new knowledge, skills and attitudes through socialisation, observation, positive interactions and participant self-regulation [42] [86] [87].

\subsection{How Does Sport Compare with Other Vehicles for Positive Youth Development?}

To enable comparison of outcomes produced by different types of organised youth activity, Larson et al. [96] surveyed 2280 Grade 11 students from 19 Illinois high schools, with selection of the schools and students within schools providing a sample that was representative of the wider Illinois community in terms of economic strata, ethnicity and residential location (urban, suburban, small city or rural). The survey documented the participation of the students in six categories of organised activity and three "control" activities. The organised activities were sport (in which $62.1 \%$ of the students participated), performance and fine arts $(45.1 \%)$, academic clubs and organisations (30.1\%), community-oriented organisations (17.3\%), service organisations (27.1\%) and faith-based youth groups (19.3\%). The control activities were academic classes in Maths or English (92.1\%) "hanging out with friends" (assumed to be 100\%) and working at a job (50.5\%). Students who were participants in two activities were required to respond to a standard survey concerning each. For students taking part in three or more activities, a computer algorithm was used to select two for comparison. The algorithm always chose the two for which the fewest direct comparisons were previously available. Although this did not completely equalize the numbers of all possible pairings, it did greatly reduce bias caused by differential participation in the various activities.

The survey relating to the activities consisted of 70 items that collectively addressed six categories of positive developmental experience (identity work, initiative, emotional regulation, teamwork and social skills, positive relationships 
and adult networks/social capital) and five categories of negative experience (stress, inappropriate adult behaviour, negative influences, social exclusion and negative group dynamics).

Of the six youth activities, sport received the highest mean score for development of initiative and the second highest for emotional regulation, but was in third to fifth position for each other category of positive developmental outcomes. Within the initiative category, $61 \%$ of the sport respondents indicated that they had learnt to "push themselves", while this outcome was reported by only $36 \%$ of respondents across all the activities. Similarly, $56 \%$ of sport respondents recounted learning that emotions affect performance, whereas this was indicated by only $41 \%$ of all youth activity respondents.

On the other hand, sport was found to produce substantially more stress than any of the other activities and was also associated with the highest levels of negative influence, social exclusion and negative group dynamics. The social exclusion component may have reflected perceived opportunities for gender interaction, since only $37 \%$ of sport respondents reported that their experience had allowed them to make friends with someone of the opposite gender, while the corresponding figure across all youth activity programs was $51 \%$.

When compared to control activities, organised sport activities always yielded higher mean scores for initiative. Mean scores for each of the other positive development experiences exceeded those for academic classes but were generally similar to those recorded for working at a job. Sport was seen to be less effective than spending leisure time with friends for identity work and development of positive relationships but, in common with other organised activities, it also produced fewer negative experiences. This was interpreted as suggesting that while spending leisure time with friends can lead to positive outcomes, absence of adult supervision may increase risk of exposure to negative influences.

Larson et al. [96] pointed out that their study served only to identify outcomes that tend to result from different types of youth development activity and should not be seen to imply that all programs of a particular type necessarily produce the same results. The detection of average differences could, however, stimulate generation and eventual testing of hypotheses concerning the reasons for their occurrence, leading to improved understanding of relationships between activity characteristics and their outcomes, and consequent enhancement of youth development programs. It does seem pertinent, for example, that among the organised youth activities evaluated by Larson et al. [96], faith-based youth groups produced the highest mean scores for five of the six positive developmental categories, and the second highest score for the other. They also produced relatively low levels of negative experience. Determining why this was the case could aid future design of other youth development programs.

The knowledge that different vehicles for youth development may lead to different outcomes, and that achievement of positive youth development through sport is contingent on the characteristics of the sport program, makes it salient 
to further explore the characteristics necessary to success.

\subsection{Models for Positive Youth Development through Sport}

Based on a literature review, Petitpas et al. [47] concluded that positive youth development through sport is most likely to occur when young people are voluntarily engaged in an appropriate setting that fosters a sense of initiative, are surrounded by caring adult mentors and a positive group or community, have opportunities to acquire skills that are transferable to other life settings, and benefit from the findings of a thorough system of evaluation and research. Also highlighted was a need to avoid "canned" program content, and note was made of the potential for youth sport programs to provide alternatives to traditional competitive sports by introducing cooperative games incorporating substantial elements of fun.

Fraser-Thomas et al. [97] incorporated the bioecological and developmental assets theories into a model for positive youth development through sport. The model emphasised the need for design and implementation of sport programs focused on building the developmental assets of youth, rather than just the teaching of sport skills. It highlighted the importance of appropriate settings and the tailoring of programs according to whether the participants were in the sampling, specializing or "investment" phase of sport participation. Additionally, it drew attention to the critical roles played by policymakers, sport organisations, coaches and parents in determining the success of the program in enhancing the Five Cs of positive youth development. In commentary concerning the model, the proponents indicated that the sport programs must be accessible to all youth and that ongoing education of coaches should be supported to ensure that they adopt a democratic coaching style and are able to teach and exemplify the life skills that they seek to develop in their charges.

Gould and Carson [48] produced a model showing that youth with pre-existing internal and external assets determining their "state" or "make-up" undergo a sport participation experience that is greatly influenced by coach characteristics and teaching strategies. The vital coach characteristics include philosophy, relationship skills (e.g., caring, listening, showing interest), competence and accessibility. Direct teaching strategies conducive to positive youth development include reinforcement, individual attention, fairness, team building, implementation of clear and consistent rules, providing youth with leadership opportunities, and involving youth in decision-making. Indirect teaching strategies include role modeling, establishment of positive social norms and setting challenges based on the demands of the sport. The sport participation experience influences the participants by fostering identity formation, a sense of belonging, personal competence, perceived self-worth and autonomy, peer group relationships and meaningful adult attachments. Also relevant is the extent to which learnings obtained as part of the sport participation experience are used or have potential to be used in other contexts. Mediated by the above effects, the sport 
participation experience leads to outcomes in the physical, intellectual and pyscho-social/emotional domains. Positive outcomes may manifest in improved physical fitness, health practices, sporting performance, school engagement and achievement, goal-setting capability, work ethic, commitment to teamwork, leadership skills, respect for others, optimism, responsibility, morality and reasoning. The model also demonstrates, however, that the sport participation experience has potential to produce negative outcomes, such as injury, over-training, disordered eating, substance abuse, school drop-out, stress, burn-out, restricted social time and excessive linking of identity to the athletic persona. Gould and Carson [48] argue that negative outcomes become much more likely when the sport program becomes directed primarily toward winning and attention to the personal development of the participants is compromised. The final component of their model relates to the transferability of outcomes produced by the sport participation experience to other life situations. Transferability is seen as essential to identification of an outcome as a genuine life skill. When it occurs, it alters the internal assets of the individual, meaning that the model incorporates a feed back loop.

A simpler but still very compelling model, termed the Personal Assets Framework, was subsequently conceived by Côté et al. [98]. The model posits that when young people take part in an activity that enables them to form meaningful relationships in an appropriate setting, their personal assets (defined as confidence, competence, connection and character) are increased, with this in turn leading to sustained participation, improved sporting performance and positive personal development. The dynamic elements of the model are therefore personal engagement in an activity, establishment of high-quality relationships and appropriate activity settings. When these elements successfully mesh, positive youth development occurs. It is suggested that personal engagement depends on the relationship between the program activities and the need of the young person for either a specialized or diversified sporting experience. Côté et al. [98] note that diversity can be provided within the context of a single sport by, for example, allowing participants to practise playing in different positions, varying the parameters of the game and focusing on a range of skill sets. They suggest that an approach founded upon diversity rather than specialization of experience is generally more beneficial to youth sport participants.

Regarding quality of relationships, Côté et al. [98] draw attention to Transformational Leadership theory, which proposes that transformational leaders provide idealized influence (in that they foster trust and respect and are seen as role models), inspirational motivation, intellectual stimulation (including encouragement of innovation and creativity) and individualized consideration of their followers. Evidence is cited that coaches with higher levels of these attributes have stronger relationships with their athletes, and are better able to develop athlete initiative, social skills, cognitive skills, and goal-setting skills. The behaviours of such coaches include consistency of demeanour, demonstration of 
care and concern for their athletes, involvement of the athletes in decision-making processes, promotion of interactive discussions, and recognition of the feelings and perspectives of individual athletes. Similarly, support of the sport activity by parents with strong transformational leadership attributes increases the likelihood of their children benefiting from the activity, and presence in the sport environment of young people with transformation leadership attributes contributes to group social cohesion and task cohesion, thereby aiding the development of peers. Côté et al. [98] point out that while the relationships of athletes to coaches, parent and peers are primary determinants of overall relationship quality in a sporting environment, interactions with other parties (e.g. officials, volunteers and administrators) also can be influential.

To illustrate the potential effect of the setting in which the sport activity takes place (i.e., the third dynamic element of the Personal Assets Framework), Côté et al. [98] refer to studies showing that elite athletes come disproportionately from cities or regions with populations of 50,000 - 100,000. They speculate that, compared to counterparts from larger cities, young people from these areas might gain an advantage from having more space for deliberate play, greater opportunity for early sampling of numerous sport activities, better integration between family, school and community in the approach to sport, and more supportive social relationships. Additionally, they raise the possibility that young people from small cities and regions may have a different frame of reference for social comparison, with evaluation of their sport performances against those of a smaller cohort increasing their perception of competence. Irrespective of the reason for the effect of location, its existence does demonstrate that the setting in which a sport activity is conducted can contribute importantly to its outcomes.

In 2017, Holt et al. [99] published the results of a meta-study incorporating a systematic review of 63 peer-reviewed articles that were focused on positive youth development in adult-supervised sport settings and contained original qualitative data. The articles related to programs conducted in 11 different nations and presented data obtained from a total of over 1000 adolescents, 700 children, 76 adult athletes, 397 adult leaders (coaches, program leaders, teachers, mentors and administrators) and 200 parents. Holt et al. [99] performed a meta-analysis of the data to identify themes describing common program characteristics and outcomes. The themes were then grouped into three categories relating to the positive youth development climate, a program focus on life skills, and positive youth development outcomes.

Within the category positive youth development climate, the themes that emerged were participant relationships with coaches and leaders, relationships with peers, and parental involvement. The importance of positive relationships with adult coaches and leaders was highlighted in as many as 19 studies. The data indicated need for an ability of the coaches and leaders to relate to program participants on an adult level rather than just as authority figures, and to demonstrate genuine care. Positive peer relationships provided program participants 
with a sense of belonging, enduring "fellowship" and opportunities for peer leadership. The nature of optimal parental involvement was less clearly defined, but there was a common perception that parents should be part of the team and can play a valuable role by reinforcing messages communicated by program staff.

Under the category of a program focus on life skills, two themes were identified, with one encompassing activities facilitating the building of life skills and the other concerned with activities enabling transfer of life skills to situations outside of sport. Building of life skills was accomplished when program coaches and leaders communicated high expectations of participant behaviour, emphasised participant accountability, served as role models for desired behaviour, used key words and phrases and demonstrably valued academic performance. Transfer of life skills was promoted by coaches having direct discussions with participants regarding the broader applicability of skills learnt in the sport setting, but there was also evidence that transfer could sometimes occur implicitly, without any attempt to deliberately focus on it.

The positive youth development outcomes extracted by Holt et al. [99] were subdivided into personal, social and physical domains. In the personal domain, the most commonly reported outcome was improvement in positive self-perception (confidence and self-esteem). Improvements in perseverance, work ethic, respect for others, independence, responsibility, attitudes, ability to make good life decisions, goal setting, problem-solving skills and stress management skills were also noted. In the social domain, the establishment of new friendships, enhanced teamwork, and increased leadership and communication skills were the most frequently observed outcomes. For the physical domain, enhancement of fundamental movement skills and of knowledge supporting active, healthy living (e.g. nutritional knowledge) were common benefits.

Holt et al. [99] combined the findings of their meta-study with contemporary theory to create a new model of positive youth development through sport. The underlying tenet of this model is that interaction of a young person with a positive youth development climate leads to building of life skills that can be transferred into positive youth development outcomes through processes explicitly designed for that purpose, implicit mechanisms, or both. In recognition of the fact that programs are ecological microsystems operating within broader societal environments, the model incorporates the concept that distal ecological systems (such as community characteristics, government and other organisational policies, and over-arching culture) influence the interaction between the individual and the positive youth development climate and therefore affect positive youth development outcomes. It also shows that positive youth development outcomes feed back to influence distal ecological processes.

In discussing their model, Holt et al. [99] note that it aligns with some earlier models, especially those of Gould and Carson [48] and Côté et al. [99], in stressing the importance of the sport participation environment as a determinant of program outcomes. 


\subsection{Did the Canberra PCYC Modified Boxing Program Have the Characteristics Needed to Engender Positive Youth Development?}

The Canberra PCYC modified boxing program had the great majority of the characteristics identified in the above literature as core elements of successful positive youth development programs. It engaged young people $1-4$ times weekly in sessions lasting $\sim 1$ hour, and for many of the young people this engagement persisted for several years. The process of their interaction with the program was therefore clearly proximal and, contextually, the program itself became part of their individual microsystems. This afforded it potential to materially influence their development, and vice versa. Importantly, participation in the program was voluntary.

The program was underpinned by principles of egalitarianism and inclusivity. It was conducted in a setting where safety was considered paramount, a message implicit in the very concept of modified boxing. The overall structure of the program in terms of both session times and the primary organisational components of specific sessions remained constant over time and were therefore predictable to participants. The coach employed a democratic coaching style and consistently engaged in discussions with participants, both individually and in small groups. Data presented both earlier in this paper and previously show that coach-participant relationships were strong, with participants perceiving the coach as caring, vitally interested in their welfare and a positive role model. Sport skill advancement was pursued primarily through use of "feedforward" techniques [100] that allowed participants to envisage improvements, rather than through traditional feed back methods focused on highlighting errors. Substantial use was made of constrained games [101] that were designed to be fun. Young participants formed strong relationships not only with the coach but also with other adults through regularly training beside them and joining with them in discussions aimed at continuous program improvement. Since the discussions visibly led to program adjustments and innovations, respect for the opinions and perspectives of youth was demonstrated. Peer relationships were positive, with some young people taking on leadership roles and thereby assisting others. Parental involvement and family connections were substantial. The study reported in this paper included four parents who were also program participants and another who regularly attended sessions as a spectator, but this was merely representative of the fact that at one stage 15 different families had at least two members involved in the program.

Building of life skills was facilitated not only by involving young people in decision-making and providing them with leadership opportunities, but also by setting clear program rules, to the extent that each new participant was initially provided with a document outlining behaviours that they could expect from their Head Coach and that he would expect from them. Key words and phrases were communicated both verbally and through signage placed on the walls of 
the program venue. For example, professionally prepared single-word signs reading Aspire, Commit, Believe, Persist, Achieve and Succeed were affixed in sequence to a wall on one side of the hall, while on the other side there were multi-word signs that included Being Together, Joy in Learning and No Limitations, Just Endless Possibilities (see Figure 5). Additionally, Australian Indigenous artwork was displayed with the intention of promoting recognition of Indigenous culture by both Indigenous and non-Indigenous program participants. Novel constrained games were designed and implemented to enable implicit learning of the skills of modified boxing and many of these games also required teamwork. The attributes of curiosity, exploration and innovation were fostered through framing of the entire program as part of a Research \& Development Centre, and through engagement of the young people in various projects aimed at acquisition of new knowledge and attendant program refinement. Training sessions were often attended by interested outside parties, including the Vice-Chancellor and senior academics from the University of Canberra, scientists from the Australian Institute of Sport, the Queensland Chief Scientist, representatives of sport technology companies, and staff members of Boxing Australia. Interaction with these visitors required young program participants to exercise and possibly extend their communication skills.

Although no explicit curriculum was developed to facilitate transfer of life skills learnt in the program environment to other situations, a message concerning the importance of a commitment to education was frequently mentioned by the

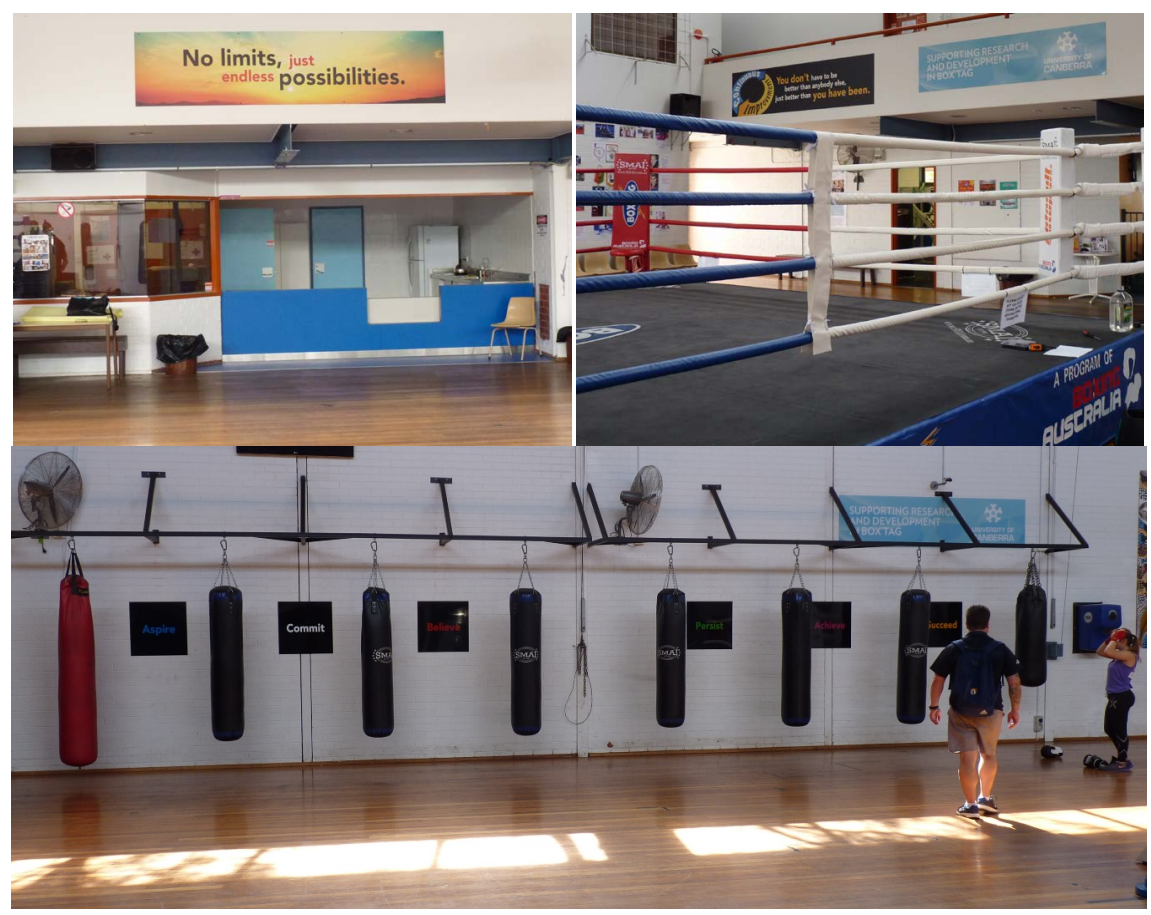

Figure 5. Examples of signage displayed on the walls of the Canberra PCYC as part of a strategy for communicating positive messages to participants in the modified boxing program. 
coach during training session and implicitly communicated by the involvement of a University as highly visible program partner. This message was continually reinforced through individual discussions with young program participants and their parents, and through establishment at the program venue of an area in which the participants could do their school homework before and/or after training. Furthermore, one adult program participant occasionally provided either full-time or part-time employment to young program participants, and this gave them opportunity to transfer their program learnings to a vocational setting.

Progressive reduction and eventual near elimination of competitive aspects of the program meant that there was little or no potential for program participants to undergo negative developmental effects that can sometimes occur in sport environments as a result of excessive focus on winning [48].

The Canberra PCYC is located adjacent to a medium-size shopping centre and an attempt was made to interest several shopkeepers in the modified boxing program so that young program participants could feel a sense of belonging not only to the program but also to the surrounding community, and the community could feel some ownership of the program. This quest produced some minor accomplishments but, for various reasons, the original vision was not fully realised.

Nevertheless, the high degree of overall alignment between the features of the Canberra PCYC modified boxing program and the identified requirements for positive youth development means that our observation of positive youth development outcomes is unsurprising.

\subsection{Were the Observed Outcomes of the Canberra Modified Boxing Program Similar to Those Previously Reported for Programs That Achieved Positive Youth Development through Sport?}

Our finding that young participants in the Canberra PCYC modified boxing program had increases in determination, self-confidence and leadership ability is in keeping with the relevant literature [48] [49] [99] [102]. It must be noted that our parameter descriptors reflect the wording used by the study subjects rather than academically accepted definitions. Consequently, our emergent theme of increased determination could be (and probably is) akin to findings of increased initiative reported by Larson et al. [96] and the increased perseverance and work ethic noted by Holt et al. [99] in their systematic review. The enhanced self-confidence that we have observed might well incorporate aspects of self-efficacy (i.e., belief in one's ability to meet challenges ahead and successfully complete tasks) and/or self-esteem (perception of acceptability), but despite this possible imprecision it certainly can be seen as falling into the category of positive self-perception, which Holt et al. [99] identified as the most common personal outcome of programs directed toward positive youth development through sport. It seems likely that there is commonality in the definition of leadership 
ability and that our observation of increase in this ability is directly comparable to increases reported elsewhere [49] [103].

We obtained evidence that some participants in the Canberra PCYC modified boxing program were able to transfer skills developed in the program environment to other settings. Two of the six young (13 - 17-year-old) subjects of our study reported improvements in school performance, with one attributing this to increased perseverance and the other to an increased recognition of the value of working hard. A third young person indicated that enhanced determination developed through the modified boxing program had proven valuable in another sport, and a fourth described a generalized realisation that good leadership entails being kind to other people. Parents, too, reported that qualities developed by their children in the program environment led to behavioural changes at home and in other settings. These observations are consistent with literature indicating that skills learnt through sport participation programs can be transferred [48] [99] [102] [104]. It must be noted, however, that transfer is a highly complex phenomenon and is not inevitable. Pierce et al. [105] point out that it is an interactive developmental process in which the individual is the integrative agent. Each individual has internal assets (e.g. demographic profile, pre-existing life skills, physical skills, personality characteristics) and external assets (e.g. family, peers, teachers, mentors, role models) that interact with multiple concurrently operative learning environments (home, school, sport, community organisations, friendship groups) to affect both the learning of life skills and the likelihood of their transfer. Factors associated with the transfer context are also influential. These include the similarity of the transfer environment to the original learning environment, the extent of opportunity to use the learned skills, support for the transfer from significant adults and peers, and the presence and nature of rewards for the transfer. Equally important are the extent to which the transfer environment stimulates unconscious personal reconstructions that lead to tacit transfer, the degree of engagement of the young person with the transfer environment, their level of confidence within that environment, the ability of the environment to satisfy their basic psychological needs (autonomy, competence and relatedness), their awareness of the transfer possibilities, and their perceptions concerning such matters as the similarity of the transfer environment to the learning environment, the presence of support for the transfer, and the meaningfulness of learning.

Two of the parents included in our study indicated that increased self-confidence exhibited by their children in the setting of the Canberra PCYC modified boxing program had not transferred to other contexts. The explanation for this probably can be found in the myriad of factors affecting transfer [105], as outlined above. It is likely that the potential transfer contexts mentioned by the parents were either too different from the Canberra PCYC modified boxing program, or were perceived by the young people as being too different, for transfer to readily occur. We cannot exclude the possibility that there may have 
been some subsequent delayed transfer as a result of the young people gradually beginning to consciously and/or unconsciously recognise program commonalities offering transfer opportunities.

\subsection{Program Features Associated with Observed Outcomes of the Canberra PCYC Modified Boxing Program}

In accordance with recommendations made by Petitpas et al. [47], we attempted to go beyond just describing the outcomes of the Canberra PCYC modified boxing program to also identify the specific program features most responsible for the outcomes. Our approach entailed determining which program features were most frequently mentioned by the subjects of our study during the conversations from which the program outcomes were discerned. Consequently, it was associative rather than mechanistic. We did not seek to assign specific outcomes to specific program features, since we believed that doing so would almost certainly lead to over-simplification.

\subsubsection{Fostering of Positive and Supportive Relationships}

The first program feature identified through our analysis was the fostering of positive and supportive relationships. This finding is consistent with much previous research [37] [39] [48] [98] [99].

\subsubsection{Collaboration}

Collaborative involvement of the young people in determining program directions emerged as the second program feature that apparently contributed substantially to the outcomes. Over the past 25 years, there has been much interest in the concept, practice and effectiveness of youth-adult partnership as a means of addressing issues of community concern. Zeldin et al. [106] define youth-adult partnership as "the practice of 1 ) multiple youth and multiple adults deliberating and acting together, 2) in a collective, democratic fashion, 3) over an extended period of time, 4) through shared work, 5) intended to promote social justice, strengthen an organisation and/or affirmatively address a community issue". They see the core elements of youth-adult partnership as authentic decision-making, natural mentors, repicrocal activity and community connectedness. Authentic decision-making requires that the voice of youth is clearly heard and genuinely influences decision-making processes. Natural mentors are non-familial adults who interact with youth by mutual consent outside of any formal mentoring arrangement, and who provide unconditional support. Reciprocal activity entails co-learning by youth and adults and often depends on the existence of structures or norms that enable critical reflection by intergenerational groups. Community connectedness refers to networks of relationships characterised by friendships, sharing of inter-cultural and ecumenical perspectives, a sense of shared cause and shared success, and development of social capital.

It is widely held that youth-adult partnership can be an effective means for both positive youth development and community development [106] [107] [108] 
[109] [110]. There have, however, been challenges associated with its successful implementation. Camino [111] notes that adults often struggle with the notion of "partnership" with youth in situations where asymmetrical power relationships have long existed (e.g., educational institutions). She contends that youth-adult partnership tends to work best when the two parties have a shared goal that is larger than themselves, such as the welfare of an entire community or collective, and do not work well when primarily focused on youth mentoring or the individual development of young people. She goes on to describe some common pitfalls of youth-adult partnerships. These include a perception on the part of adults that youth should take on all the important roles, ascription to a false notion that empowering youth requires adults to give up power, creation of youth stereotypes that limit perception of the roles that youth can play in the partnership, and failure to recognise that partnership can benefit not only youth development but also adult development. Zeldin et al. [106] caution that youth-adult partnership should not be confused with "youth participation" or "youth engagement" since the latter terms can accommodate a level of youth involvement below that necessary for partnership.

We believe that in the context of the Canberra PCYC modified boxing program, a true youth-adult partnership was achieved. It was made possible by having youth and adults take part in training sessions and follow-up discussions together, and by their common status as program participants irrespective of their age. The discussions were focused on the shared goal of continuous program improvement. The willingness of young participants to contribute to the conversations was perhaps facilitated by the fact that in training sessions their physical abilities overlapped with those of the adults. This may have fostered perceptions of equality. Authenticity of decision-making was demonstrated through program adjustments reflecting participant feed back and ideas, and this was specifically recognised by all the young subjects of the current study. The presence of numerous adults in the training and discussion environments provided a rich source of potential natural mentors for youth. Our data show that strong natural mentoring relationships were formed and were valued by both youth and adults. There was substantial reciprocal activity entailing joint participation of youth and adults in a co-learning environment that included formal and informal involvement in various research endeavours. Community connectedness is clearly revealed in our data set through multiple references to meaningful connections with a range of adults and peers in the program environment and through statements about everyone looking after each other.

Zeldin et al. [106] cite evidence indicating that participation in successful youth-adult partnerships can enhance numerous positive youth characteristics including skill learning, identity exploration, initiative, emotional well-being, development of agency and, notably in the current context, self-confidence.

The reciprocal activity aspect of the youth-adult partnership embodied in the Canberra PCYC modified boxing program merits further attention. It essentially 
took the form of a communal design exercise directed at producing a program that was ever more effective in meeting the needs and wishes of its participants. Design methodology has evolved over the years to encompass increasingly more interaction with future users of the design outcomes [112]. This trend found early expression in the concept of user-centred design, in which designers consult with selected potential users to enable clear understanding of their requirements. This consultation tends to occur at an early stage of the design process, with further "touch points" occurring when decisions have to be made. Creativity remains largely the domain of the designer. A different approach has recently gained impetus based on the notion that value can be gained by involving users not just at moments of decision but also in idea generation and the entire creative endeavour. It is argued that in a world where product design is becoming less important than design of the user experience, comprehensive engagement with users as "the experts of their own experience" is logical. The more participatory approach has become known as "co-design" and is considered to be an example of "co-creativity". Some proponents of co-design have chosen to interact closely with a few "lead users" regarded as very creative. Sanders and Stappers [112] contend, however, that all people are creative, and that advantage can be obtained from a highly inclusive co-design process since it can provide a more diverse and representative perspective. They note that there are differences between people in the level of creativity that they are able and willing to invest in a specific activity at a specific time, and suggest that maximising overall input by accommodating and catering for these differences can aid effective co-design. They emphasise that users must be provided with appropriate tools to express themselves. Sanders and Simons [113] argue that where the purpose of co-design is to create social value, the tools must permit direct personal involvement of experts with everyday people, and that empathy between the co-designers is crucial. An important difference between user-centred design and co-design is that in the former the roles of researcher and designer are largely separate, whereas in the latter they are closely integrated and can even be performed by one person [112].

Iteration of the Canberra PCYC modified boxing program clearly entailed co-design since content initially derived from other settings was progressively refined through almost daily interaction between the coach and program participants, and through regular dialogue between these parties and content experts. Every program participant was consulted through informal conversations as well as formal group meetings and one-on-one discussions. The consultation provided opportunity not just for input to decision-making but also for advancing and honing ideas. It covered topics ranging from program activities to development of specialized equipment and even program promotion. It was maintained over several years and genuinely allowed program participants to become architects of their own experience. The level of creativity varied between participants and even within participants over time. Some young program members made substantial contributions. In common with an observation reported by Bovill 
[114] in a different setting, we found that the co-design process led to considerable participant ownership of the outcome. For example, it became common for participants-including adolescents-to refer to "our program" rather than "the program".

The practices of co-creativity and co-design are now being adopted in multiple fields, including the development of healthcare environments [115], corporate workplaces [116], educational environments and curricula [114], computer games and movies [117], and applied theatre for marginalized youth [118], but following a literature search we suspect that our work at the Canberra PCYC might constitute their first use in the development of a sport program.

In summary, we submit that collaboration in our context was innovative in entailing a co-design process within the scope of an informal but very effective youth-adult partnership.

\subsubsection{Opportunities for Observational Learning}

The final theme concerning Canberra PCYC modified boxing program characteristics associated with the observed positive youth development outcomes is the provision of opportunities for observational learning. The emergence of this theme is consistent with Bandura's Observational Learning Theory [119], which suggests that learning can occur through watching others. The learning takes place through a four-step process in which an individual first notices something of perceived relevance, then remembers what was noticed because it is considered to have merit or value, produces a copy of what was noticed, and experiences a consequence that increases the likelihood that the behaviour will occur again [119]. The consequence must entail "intrinsic reinforcement" in the form of an internal reward such as satisfaction, pride and a sense of achievement.

Observational learning is considered dependent on information processing, which occurs between observing the behaviour (stimulus) and deciding to imitate it or not (response). Bandura and his colleagues demonstrated this point with their famous bobo doll experiment [120] in which 72 pre-school aged children saw an adult model acting aggressively toward a soft inflatable doll. There were three experimental conditions-one in which the children observed a second adult praise the aggressive model and provide a treat for a "great performance", one in which a second adult reprimanded the model for the aggressive behaviour, and one in which there was no second adult and the children simply observed the aggressive behaviour. Later, each child was left alone in a room with the doll and the props used by the aggressive adult. It was found that children who had witnessed the model-rewarded and no-consequence conditions were more inclined to imitate the aggressive actions compared to children who had witnessed the model-punished condition. The researchers concluded that motivational factors influenced the relationship between stimulus and response and accounted for the different behaviours.

According to Bandura et al. [120], observational learning can occur not only through live modelling (where an individual actually observes a particular type 
of behaviour), but also through verbal instruction modelling (where an individual receives a verbal description of the behaviour) and symbolic modelling (where an individual observes behaviour displayed by real or fictional characters in books and/or visual media).

Several of the young subjects of our study mentioned that they had learnt valuable lessons from watching their coach and other participants in the Canberra PCYC modified boxing program, and one of the parents opined that the behaviours of his son had been positively influenced by observing those of an adult informal mentor. Although many of these comments were made in the context of discussions concerning the development of leadership skills by the young people, it seems likely that observing the determination and work ethic exhibited by admired peers and adults during training sessions contributed to adoption of these behaviours, and that consequent positive feed back from fellow program participants and the coach served to reinforce them. Satisfaction deriving from completion of challenging sessions, and longer-term perception of improvements in physical fitness, may have been important in providing the necessary intrinsic reinforcement.

\subsection{Interaction of the Canberra PCYC Modified Boxing Program with Distal Ecological Systems}

In keeping with the bioecological theory and the model developed by Holt et al. [99] to conceptualise positive youth development through sport, distal ecological systems did affect the outcomes of the Canberra PCYC modified boxing program. The program operated within a societal culture where participation in sport and exercise is highly valued. It was facilitated by a Canberra PCYC funding initiative that enabled young people of low socio-economic status to access the program. These distal factors aided participant recruitment. In turn, the extensive recruitment and positive outcomes achieved by our program favourably influenced the broader Canberra PCYC ecology.

\subsection{Effect of Time on Interactive Processes in the Canberra PCYC Modified Boxing Program Environment}

Time was undoubtedly an important determinant of outcomes derived from interactive processes taking place in the environment of the Canberra PCYC modified boxing program, as predicted by the bioecological theory [34] [36]. A key strength of the program was that it ran for almost five years, with many participants regularly involved for three or more years [5]. Consequently, there was time for developmental outcomes to occur and undergo consolidation. It is also true, however, that both the program environment and the people interacting with it underwent time-related change, partly due to their continuously evolving effects on each other, but also because each was influenced also by other factors. As previously noted, the primary emphasis of the program gradually changed toward achievement of social and personal developmental objectives, as opposed 
to the advancement of modified boxing. Individual program participants were subject to biological and socio-psychological change. Proximal person-environment interactions occurring in the contextual micro-system were therefore inevitably altered, at least in subtle ways. Distal interactive processes were also affected, with perhaps the most profound being that in the later stages of the program the Canberra PCYC made a financially driven strategic decision to reduce the floor space allocated to the program. This influenced the microsystem and contributed to eventual program closure.

Also relevant to the issue of time is a question concerning the extent to which a sport program confined to $1-4$ hours per week could be expected to positively influence the lives of young people who might be in adverse circumstances for much greater amounts of time. Firstly, it needs to be pointed out that for many of the young participants in the Canberra PCYC modified boxing program the interactions with their coach and fellow program participants extended well beyond formal session times, since it also encompassed discussions before and after sessions and, in many cases, other forms of contact including telephone conversations, email communication, social media dialogue and joint attendance of social events. Within friendship groups (some of which existed before the young people enrolled in the program) and family units, casual conversations occurring outside of the program environment likely served to increase effective time of engagement with the program and reinforce program commitment. In any case, Gilligan [121] has argued that debilitating adversity often results from the cumulative effects of multiple negative experiences, and that in such situations the introduction of even a single and seemingly small positive experience can have a decisive impact.

\subsection{Incidental Nature of Positive Development through the Canberra PCYC Modified Boxing Program}

The Canberra PCYC modified boxing program was never specifically designed as a positive youth development initiative. Rather, the early emphasis was on recruiting and retaining participants to meet a performance criterion set by Canberra PCYC management. The decision to have people of varying ages and levels of physical ability train together was entirely pragmatic, stemming from the fact that there was only one available coach. Continual consultation with participants and associated program refinements were implemented primarily as strategies for maximising participant retention. We had very limited awareness of the extant youth development literature. Indeed, we began investigating that literature only after receiving anecdotal reports that young program participants were benefiting from their involvement in ways that extended beyond the immediate program context. From that point onward, inputs of the coach to his regular discussions with participants were undoubtedly somewhat influenced by his evolving perspectives, but practical considerations and responsiveness to participant comments remained paramount in program iteration. It is intriguing that this orientation yielded a program that strongly aligned with positive youth de- 
velopment criteria identified by others through academic research. It is tempting to suggest that when a reasonably large group of young people and adults with a recreational sport focus collaborate effectively over a long period to construct a mutually beneficial sport program, there may be a tendency for the "wisdom of the crowd" [122] to produce a design that favours achievement of incidental positive youth development outcomes. Future research could test this proposition, while also enabling increased understanding of environmental factors that may shape not only the design itself but also the fidelity and effectiveness of its implementation.

It is sometimes argued that for a program to qualify as a positive youth development initiative, it must have a primary focus on attaining positive youth development goals [28] [123]. In a strict sense, the Canberra PCYC modified boxing program did not satisfy this condition, since its positive youth development goals were not explicit and, if implicit, were subsumed within broader objectives. It is arguable, though, that a case exists for defining a program based on its outcomes rather than its intent. The findings of the present study show that the Canberra PCYC program did serve as an effective instrument for positive youth development.

\section{Conclusions}

We conclude that when youth and adults participate jointly in a community-focused sport program, are encouraged to contribute to the ongoing design and refinement of the program, and see that their inputs are influencing practice, positive youth development outcomes can occur. Such outcomes may depend, however, on a range of other factors, including the way in which the program is coached, the characteristics of the training environment, the level of support from the host organisation and the extent to which the group becomes a cohesive community.

It appears that when youth and adults are all simply participants in a sport program and not demarcated by age, typical age-associated power imbalances may be minimised, giving youth a greater voice and an increased opportunity to take on leadership roles. It is also clear, however, that some young people greatly value the opportunity to learn from trusted and admired adults as part of a sport experience.

A sport program can be popular in the absence of interpersonal competition. When permitted to contribute to shaping their own sporting context, some young people prefer to create an environment in which they compete only against themselves by striving for personal performance improvements with strong support from their coaches, peers and other program members. Since such an environment may allow realisation of the major benefits of sport while decreasing its potential downside, it might be particularly conducive to positive youth development.

As the role of recreational sport in contemporary society undergoes progres- 
sive change toward enabling participants to meet physical fitness and socio-psychological needs, there may be an increasing requirement for initiatives incorporating key aspects of the Canberra PCYC modified boxing program. While the latter was a derivation of boxing, this was due primarily to the background of the first author of this paper, and to perception that an association with boxing could be attractive to the target demographic. Over time, the program became increasingly distant from traditional boxing culture and practices. In the future, therefore, programs based on similar operational principles could be built around other sports or could have a multi-sport focus. This might even increase the appeal, as the nominal link of our program to boxing occasionally elicited pushback from potential supporters. Any new program will need to be carefully monitored and evaluated, since nuanced differences from our initiative could lead to different outcomes.

In view of the evident effects of the Canberra PCYC modified in accomplishing positive youth development, future experimentation with similar concepts would seem well-justified.

\section{Limitations}

We acknowledge that our study has several limitations. Firstly, the findings are derived from a very small, targeted sample of participants and therefore cannot be considered as necessarily providing a representative view of all the people who were involved with the program. Secondly, we did not investigate possible influence of other activities in which participants were engaged on the reported findings. This additional information could have added to the richness of the data, perhaps providing a more detailed explanation for the emergent themes by allowing assessment of the extent to which the values promoted by the program were concurrently being fostered in other learning environments (e.g., schools, families and community organisations). Thirdly, we concentrated our attention on the environmental factors influencing person-environment interactions. We did not comprehensively document the baseline personal characteristics and circumstances of our subjects or monitor changes in these parameters over time, so were unable to determine the extent to which the internal and external assets of the subjects may have contributed to the observed outcomes. Our findings do indicate, however, that a few specific developmental outcomes (increased levels of determination, improved self-confidence and enhanced leadership skills) were relatively common. This suggests that commonality in proximal processes associated with the program outweighed differences in personal characteristics in the shaping program outcomes, as would be predicted by the bioecological theory. Finally, the presented evidence pertains to a specific community-based sports program and should be considered as having vertical generalizability (contributing to the building of interpretative theory) and not horizontal generalizability (applicability across multiple settings) [124]. Readers should consider the ability of the findings to resonate with their own experiences, provide insights 
into the investigated phenomenon and contribute to evaluation of existing theories, rather than concentrating primarily on how relevant they might be to other times and settings [125] [126] [127].

\section{Acknowledgements}

The authors are grateful to the Canberra Police Community Youth Club for hosting the modified boxing program that forms the basis of this paper and for allowing the first author to dedicate much of his work to the research and continued refinement of that program. They also wish to thank the participants in the program for their commitment and passion over its duration, and for the support and friendship that they gave to the first author in his role as program coach and to both authors in their role as researchers. Professor Keith Lyons, Dr Richard Keegan and Dr Christopher Barnes of the University of Canberra assisted the study through regular provision of much-appreciated advice.

\section{Conflicts of Interest}

The authors declare no conflicts of interest regarding the publication of this paper.

\section{References}

[1] Hahn, A.G., Helmer, R.J., Mackintosh, C., Staynes, L.M. and Blanchonette, I. (2011) Technological Foundations and Current Status of a Modified, Low-Risk Form of Competitive Boxing (Box’Tag ${ }^{\bowtie}$ ). Sports Technology, 4, 178-184.

https://doi.org/10.1080/19346182.2012.725413

[2] Perkins, P., Helmer, R.J.N., Mackintosh, C. and Hahn, A.G. (2017) Reflections on Long-Term Development and Use of Automated Scoring Technology in a Sport (Modified Boxing) Context. World Journal of Engineering and Technology, 5, 455-480. https://doi.org/10.4236/wjet.2017.53040

[3] Perkins, P., Hahn, A., Keegan, R. and Collis, I. (2014) Why Do Community-Based Athletes Choose to Participate in a Modified, Low-Risk Form of Boxing? An Interpretative Phenomenological Analysis. Journal of Research in Humanities and Social Science, 2, 60-69. https://doi.org/10.9790/9467-2116069

[4] Perkins, P., Hahn, A.G. and Keegan, R. (2015) What Are the Perceived Coaching Practices That Have Contributed to Participation in a Modified Low-Risk Form of Boxing? An Interpretive Phenomenological Analysis. Journal of Sports and Physical Education, 2, 46-55.

[5] Perkins, P. and Hahn, A. (2019) Factors Underpinning at Least Three Years of Participant Adherence to a Community-Focused Modified Boxing Program. Open Journal of Social Sciences, 7, 298-331. https://doi.org/10.4236/jss.2019.72023

[6] Campbell, K. (2013) Why We Need More Practitioner Research: A Response to "A Teacher Educator Uses Action Research to Develop Culturally Conscious Curriculum Planners”. Democracy and Education, 21, Article 7.

[7] DeLyser, D. (2001) “Do You Really Live Here?” Thoughts on Insider Research. Geographical Review, 91, 441-453. https://doi.org/10.2307/3250847

[8] Whittemore, R., Chase, S.K. and Mandle, C.L. (2001) Validity in Qualitative Research. Qualitative Health Research, 11, 522-537. 
https://doi.org/10.1177/104973201129119299

[9] Packer, M.J. and Goicoechea, J. (2000) Sociocultural and Constructivist Theories of Learning: Ontology, Not Just Epistemology. Educational Psychologist, 35, 227-241. https://doi.org/10.1207/S15326985EP3504_02

[10] Polkinghorne, D.E. (1989) Phenomenological Research Methods. In: Valle, R.S. and Halling, S., Eds., Existential-Phenomenological Perspectives in Psychology, Springer US, Boston, 41-60. http://link.springer.com/10.1007/978-1-4615-6989-3_3 https://doi.org/10.1007/978-1-4615-6989-3_3

[11] Gilgun, J.F. (2008) Lived Experience, Reflexivity, and Research on Perpetrators of Interpersonal Violence. Qualitative Social Work. Research and Practice, 7, 181-197. https://doi.org/10.1177/1473325008089629

[12] Elmir, R., Schmied, V., Jackson, D. and Wilkes, L. (2011) Interviewing People about Potentially Sensitive Topics. Nurse Researcher, 19, 12-16. https://doi.org/10.7748/nr2011.10.19.1.12.c8766

[13] Naional Health and Medical Research Council, Australian Research Council, Australian Vice-Chancellors' Committee (2007) National Statement on Ethical Conduct in Human Research. Canberra.

https://www.nhmrc.gov.au/about-us/publications/national-statement-ethical-condu ct-human-research-2007-updated-2018

[14] Braun, V. and Clarke, V. (2006) Using Thematic Analysis in Psychology. Qualitative Research in Psychology, 3, 77-101. https://doi.org/10.1191/1478088706qp063oa

[15] Smith, J.A. and Osborn, M. (2003) Interpretative Phenomenological Analysis. In: Qualitative Psychology: A Practical Guide to Methods, 2nd Edition, Sage Publications, London, 53-80.

[16] Tuckett, A.G. (2005) Applying Thematic Analysis Theory to Practice: A Researcher's Experience. Contemporary Nurse, 19, 75-87. https://doi.org/10.5172/conu.19.1-2.75

[17] Nowell, L.S., Norris, J.M., White, D.E. and Moules, N.J. (2017) Thematic Analysis: Striving to Meet the Trustworthiness Criteria. International Journal of Qualitative Methods, 16, 1-13. https://doi.org/10.1177/1609406917733847

[18] Canberra PCYC ModBox Participants (2015) Realising Our Potential. Canberra. https://youtu.be/dryCItJZs8o

[19] Canberra PCYC ModBox Participants (2015) No Limits, Just Endless Possibilities. Canberra. https://youtu.be/xWIOR56BCU4

[20] King, N. (2004) Using Templates in Thematic Analysis of Text. In: Essential Guide to Qualitative Methods in Organizational Research, Sage Publications, London, 257-270. https://doi.org/10.4135/9781446280119.n21

[21] Aronson, J.A. (1995) Pragmatic View of Thematic Analysis. The Qualitative Report, 2, 1-3.

[22] Bandura, A. (1977) Social Learning Theory. Prentice Hall, Oxford, 264 p.

[23] Seligman, M. and Csikszentmihalyi, M. (2000) Positive Psychology: An Introduction. American Psychologist, 55, 5-14. https://doi.org/10.1037/0003-066X.55.1.5

[24] Alex Linley, P., Joseph, S., Harrington, S. and Wood, A.M. (2006) Positive Psychology: Past, Present, and (Possible) Future. The Journal of Positive Psychology, 1, 3-16. https://doi.org/10.1080/17439760500372796

[25] Strümpfer, D.J.W. (2005) Standing on the Shoulders of Giants: Notes on Early Positive Psychology (Psychofortology). South African Journal of Psychology, 35, 21-45. 
https://doi.org/10.1177/008124630503500102

[26] Damon, W. (2004) What Is Positive Youth Development? The Annals of the American Academy of Political and Social Science, 591, 13-24. https://doi.org/10.1177/0002716203260092

[27] Dymnicki, A.B., Le Menestrel, S., Boyd, M.J., Lauxman, L., Oberlander, S.E. and Osher, D.M. (2016) Developing a Federal Research Agenda for Positive Youth Development: Identifying Gaps in the Field and an Effective Consensus Building Approach. Journal of Youth Development, 11, 5-19. https://doi.org/10.5195/JYD.2016.430

[28] Catalano, R.F., Berglund, M.L., Ryan, J.A.M., Lonczak, H.S. and Hawkins, J.D. (2004) Positive Youth Development in the United States: Research Findings on Evaluations of Positive Youth Development Programs. Annals of the American Academy of Political and Social Science, 591, 98-124. https://doi.org/10.1177/0002716203260102

[29] Resnick, M.D. (2000) Protective Factors, Resiliency, and Healthy Youth Development. Adolescent Medicine: State of the Art Reviews, 11, 157-164.

[30] Bronfenbrenner, U. (1977) Toward an Experimental Ecology of Human Development. American Psychologist, 32, 513. https://doi.org/10.1037/0003-066X.32.7.513

[31] Bronfenbrenner, U. (1993) The Ecology of Cognitive Development: Research Models and Fugitive Findings. In: Development in Context. Acting and Thinking in Specific Environments, Erlbaum, Hillsdale, 3-44.

[32] Bronfenbrenner, U. and Ceci, S.J. (1994) Nature-Nurture Reconceptualised in Developmental Perspective: A Bioecological Model. Psychological Review, 101, 568-586. https://doi.org/10.1037/0033-295X.101.4.568

[33] Bronfenbrenner, U. (1995) Developmental Ecology through Space and Time: A Future Perspective. In: Examining Lives in Context. Perspectives on the Ecology of Human Development, American Psychological Association, Washington DC, 619-648. https://doi.org/10.1037/10176-018

[34] Bronfenbrenner, U. and Morris, P.A. (1998) The Ecology of Developmental Processes. In: Handbook of Child Psychology, 5th Edition, John Wiley and Sons, New York, 993-1023.

[35] Bronfenbrenner, U. (1999) Environments in Developmental Perspective: Theoretical and Operational Models. In: Measuring Environment across the Life Span, American Psychological Association, Washington DC, 3-28. https://doi.org/10.1037/10317-001

[36] Tudge, J.R.H., Mokrova, I., Hatfield, B.E. and Karnik, R.B. (2009) Uses and Misuses of Bronfenbrenner's Bioecological Theory of Human Development. Journal of Family Theory \& Review, 1, 198-210. https://doi.org/10.1111/j.1756-2589.2009.00026.x

[37] Lerner, R.M., von Eye, A., Lerner, J.V., Lewin-Bizan, S. and Bowers, E.P. (2010) Special Issue Introduction: The Meaning and Measurement of Thriving: A View of the Issues. Journal of Youth and Adolescence, 39, 707-719.

https://doi.org/10.1007/s10964-010-9531-8

[38] Waid, J. and Uhrich, M. (2019) A Scoping Review of the Theory and Practice of Positive Youth Development. The British Journal of Social Work, bcy130. https://academic.oup.com/bjsw/advance-article/doi/10.1093/bjsw/bcy130/5304553 https://doi.org/10.1093/bjsw/bcy130

[39] Lerner, R.M., Lerner, J.V., Almerigi, J.B., Theokas, C., Phelps, E., Gestsdottir, S., et al. (2005) Positive Youth Development, Participation in Community Youth Devel- 
opment Programs, and Community Contributions of Fifth-Grade Adolescents: Findings from the First Wave of the 4-H Study of Positive Youth Development. Journal of Early Adolescence, 25, 17-71. https://doi.org/10.1177/0272431604272461

[40] Phelps, E., Balsano, A.B., Fay, K., Peltz, J.S., Zimmerman, S.M., Lerner, R.M., et al. (2007) Nuances in Early Adolescent Developmental Trajectories of Positive and Problematic/Risk Behaviors: Findings from the 4-H Study of Positive Youth Development. Child and Adolescent Psychiatric Clinics of North America, 16, 473-496. https://doi.org/10.1016/j.chc.2006.11.006

[41] Urban, J.B., Lewin-Bizan, S. and Lerner, R.M. (2009) The Role of Neighborhood Ecological Assets and Activity Involvement in Youth Developmental Outcomes: Differential Impacts of Asset Poor and Asset Rich Neighborhoods. Journal of Applied Developmental Psychology, 30, 601-614. https://doi.org/10.1016/j.appdev.2009.07.003

[42] Coakley, J. (2011) Youth Sports: What Counts as “Positive Development?" Journal of Sport and Social Issues, 35, 306-324. https://doi.org/10.1177/0193723511417311

[43] Christens, B.D. and Dolan, T. (2011) Interweaving Youth Development, Community Development, and Social Change through Youth Organizing. Youth \& Society, 43, 528-548. https://doi.org/10.1177/0044118X10383647

[44] Eccles, J.S., Gootman, J.A., National Research Council, Institute of Medicine (2002) Community Programs to Promote Youth Development. National Academy Press, Washington DC, $411 \mathrm{p}$.

[45] Côté, J. and Hancock, D.J. (2016) Evidence-Based Policies for Youth Sport Programmes. International Journal of Sport Policy and Politics, 8, 51-65. https://doi.org/10.1080/19406940.2014.919338

[46] Fraser-Thomas, J. and Côté, J. (2006) Youth Sports: Implementing Findings and Moving Forward with Research. Athletic Insight, 8, 12-27.

[47] Petitpas, A.J., Cornelius, A.E., Van Raalte, J.L. and Jones, T. (2005) A Framework for Planning Youth Sport Programs That Foster Psychosocial Development. The Sport Psychologist, 19, 63-80. https://doi.org/10.1123/tsp.19.1.63

[48] Gould, D. and Carson, S. (2008) Life Skills Development through Sport: Current Status and Future Directions. International Review of Sport and Exercise Psycholo$g y$, 1, 58-78. https://doi.org/10.1080/17509840701834573

[49] Hansen, D.M., Larson, R.W. and Dworkin, J.B. (2003) What Adolescents Learn in Organized Youth Activities: A Survey of Self-Reported Developmental Experiences. Journal of Research on Adolescence, 13, 25-55. https://doi.org/10.1111/1532-7795.1301006

[50] Weiss, M.R. and Wiese-Bjornstal, D.M. (2009) Promoting Positive Youth Development through Physical Activity. President's Council on Physical Fitness and Sports Research Digest, 10, 1-8.

[51] Richman, E.L. and Shaffer, D.R. (2000) If You Let Me Play Sports: How Might Sport Participation Influence the Self-Esteem of Adolescent Females? Psychology of Women Quarterly, 24, 189-199. https://doi.org/10.1111/j.1471-6402.2000.tb00200.x

[52] Hodge, K., Danish, S. and Martin, J. (2013) Developing a Conceptual Framework for Life Skills Interventions. The Counseling Psychologist, 41, 1125-1152. https://doi.org/10.1177/0011000012462073

[53] Hodge, K. and Danish, S. (1999) Promoting Life Skills for Adolescent Males through Sport. In: Handbook of Counseling Boys and Adolescent Males: A Practitioner's Guide, Sage Publications, Thousand Oaks, 55-71. 
https://doi.org/10.4135/9781452220390.n4

[54] Papacharisis, V., Goudas, M., Danish, S.J. and Theodorakis, Y. (2005) The Effectiveness of Teaching a Life Skills Program in a Sport Context. Journal of Applied Sport Psychology, 17, 247-254. https://doi.org/10.1080/10413200591010139

[55] Eccles, J.S., Barber, B.L., Stone, M. and Hunt, J. (2003) Extracurricular Activities and Adolescent Development. Journal of Social Issues, 59, 865-889. https://doi.org/10.1046/j.0022-4537.2003.00095.x

[56] Segrave, J.O. (1983) Sport and Juvenile Delinquency. Exercise and Sport Sciences Reviews, 11, 181. https://doi.org/10.1249/00003677-198301000-00007

[57] Pate, R.R., Trost, S.G., Levin, S. and Dowda, M. (2000) Sports Participation and Health-Related Behaviors among US Youth. Archives of Pediatrics \& Adolescent Medicine, 154, 904. https://doi.org/10.1001/archpedi.154.9.904

[58] Rainey, C.J., McKeown, R.E., Sargent, R.G. and Valois, R.F. (1996) Patterns of Tobacco and Alcohol Use among Sedentary, Exercising, Nonathletic, and Athletic Youth. Journal of School Health, 66, 27-32. https://doi.org/10.1111/j.1746-1561.1996.tb06254.x

[59] Veliz, P.T., Boyd, C.J. and McCabe, S.E. (2015) Competitive Sport Involvement and Substance Use among Adolescents: A Nationwide Study. Substance Use \& Misuse, 50, 156-165. https://doi.org/10.3109/10826084.2014.962049

[60] Janssen, I. and LeBlanc, A.G. (2010) Systematic Review of the Health Benefits of Physical Activity and Fitness in School-Aged Children and Youth. International Journal of Behavioral Nutrition and Physical Activity, 7, 40. https://doi.org/10.1186/1479-5868-7-40

[61] Marques, A., Ekelund, U. and Sardinha, L.B. (2016) Associations between Organized Sports Participation and Objectively Measured Physical Activity, Sedentary Time and Weight Status in Youth. Journal of Science and Medicine in Sport, 19, 154-157. https://doi.org/10.1016/j.jsams.2015.02.007

[62] Branta, C.F., Lerner, J.V. and Taylor, C.S. (1996) Physical Activity and Youth Sports: Social and Moral Issues. Peace and Conflict. Journal of Peace Psychology, 2, 301-303. https://doi.org/10.1207/s15327949pac0204_2

[63] Loprinzi, P.D., Cardinal, B.J., Loprinzi, K.L. and Lee, H. (2012) Benefits and Environmental Determinants of Physical Activity in Children and Adolescents. Obesity Facts, 5, 597-610. https://doi.org/10.1159/000342684

[64] Fraigenbaum, A.D., Westcott, W.L., LaRosa Loud, R. and Long, C. (1999) The Effects of Different Resistance Training Protocols on Muscular Strength and Endurance Development in Children. Pediatrics, 104, e5. https://doi.org/10.1542/peds.104.1.e5

[65] Mohamed, H., Vaeyens, R., Matthys, S., Multael, M., Lefevre, J., Lenoir, M., et al. (2009) Anthropometric and Performance Measures for the Development of a Talent Detection and Identification Model in Youth Handball. Journal of Sports Sciences, 27, 257-266. https://doi.org/10.1080/02640410802482417

[66] Boreham, C. and Riddoch, C. (2001) The Physical Activity, Fitness and HEALTH of Children. Journal of Sports Sciences, 19, 915-929. https://doi.org/10.1080/026404101317108426

[67] Merkel, D. (2013) Youth Sport: Positive and Negative Impact on Young Athletes. Open Access Journal of Sports Medicine, 4, 151-160.

https://doi.org/10.2147/OAJSM.S33556

[68] Edwards, L.C., Bryant, A.S., Keegan, R.J., Morgan, K., Cooper, S.-M. and Jones, 
A.M. (2018) "Measuring” Physical Literacy and Related Constructs: A Systematic Review of Empirical Findings. Sports Medicine, 48, 659-682. https://doi.org/10.1007/s40279-017-0817-9

[69] Vandorpe, B., Vandendriessche, J., Vaeyens, R., Pion, J., Matthys, S., Lefevre, J., et al. (2012) Relationship between Sports Participation and the Level of Motor Coordination in Childhood: A Longitudinal Approach. Journal of Science and Medicine in Sport, 15, 220-225. https://doi.org/10.1016/j.jsams.2011.09.006

[70] Siegenthaler, K.L. and Gonzalez, G.L. (1997) Youth Sports as Serious Leisure: A Critique. Journal of Sport and Social Issues, 21, 298-314. https://doi.org/10.1177/019372397021003006

[71] Begg, D.J., Langley, J.D., Moffitt, T. and Marshall, S.W. (1996) Sport and Delinquency: An Examination of the Deterrence Hypothesis in a Longitudinal Study. British Journal of Sports Medicine, 30, 335-341. https://doi.org/10.1136/bjsm.30.4.335

[72] O’Brien, K.S., Blackie, J.M. and Hunter, J.A. (2005) Hazardous Drinking in Elite New Zealand Sportspeople. Alcohol and Alcoholism, 40, 239-241. https://doi.org/10.1093/alcalc/agh145

[73] Shields, D.L.L. and Bredemeier, B.J.L. (1995) Character Development and Physical Activity. Human Kinetics Publishers, Champaign, XI, 269.

[74] Bredemeier, B.J. and Shields, D.L. (1987) Moral Growth through Physical Activity: A Structural Developmental Approach. In: Advances in Pediatric Sport Sciences, Human Kinetics, Champaign, 143-165.

[75] DuRant, R.H. (1992) Findings from the Preparticipation Athletic Examination and Athletic Injuries. Archives of Pediatrics \& Adolescent Medicine, 146, 85. https://doi.org/10.1001/archpedi.1992.02160130087027

[76] Wankel, L.M. and Kreisel, P.S.J. (1985) Factors Underlying Enjoyment of Youth Sports: Sport and Age Group Comparisons. Journal of Sport Psychology, 7, 51-64. https://doi.org/10.1123/jsp.7.1.51

[77] Doty, J. (2006) Sports Build Character. Journal of College and Character, 7, 1-9. https://doi.org/10.2202/1940-1639.1529

[78] Brustad, R.J. (1988) Affective Outcomes in Competitive Youth Sport: The Influence of Intrapersonal and Socialization Factors. Journal of Sport and Exercise Psychology, 10, 307-321. https://doi.org/10.1123/jsep.10.3.307

[79] Gould, D. and Petlichkoff, L. (1988) Participation Motivation and Attrition in Young Athletes. In: Children in Sport, 3rd Edition, Human Kinetics, Champaign, 161-178.

[80] Gould, D. (1987) Understanding Attrition in Children's Sport. In: Advances in Pediatric Sport Sciences. Behavioral Issues, Human Kinetics, Champaign, 61-85.

[81] Callender, S.S. (2010) The Early Specialization of Youth Sports. Athletic Training and Sports Health Care, 2, 255-257. https://doi.org/10.3928/19425864-20100428-03

[82] Hedstrom, R. and Gould, D. (2004) Research in Youth Sports: Critical Issues Status. Institute for the Study of Youth Sports, Michigan State University, East Lansing. http://www.hollistonsoccer.org/wp-content/uploads/2014/05/CriticalIssuesYouthSp orts-2.pdf

[83] Gonçalves, C.E.B., Rama, L.M.L. and Figueiredo, A.B. (2012) Talent Identification and Specialization in Sport: An Overview of Some Unanswered Questions. International Journal of Sports Physiology and Performance, 7, 390-393. https://doi.org/10.1123/ijspp.7.4.390 
[84] Wiersma, L.D. (2000) Risks and Benefits of Youth Sport Specialization: Perspectives and Recommendations. Pediatric Exercise Science, 12, 13-22. https://doi.org/10.1123/pes.12.1.13

[85] Paylor, I. (2010) A Discussion Paper on Promoting Sport and Physical Activity as Part of the Role of the Social Work Sector. International Journal of Health Promotion and Education, 48, 85-93. https://doi.org/10.1080/14635240.2010.10708187

[86] Collins, D., Bailey, R., Ford, P.A., MacNamara, Á., Toms, M. and Pearce, G. (2012) Three Worlds: New Directions in Participant Development in Sport and Physical Activity. Sport, Education and Society, 17, 225-243. https://doi.org/10.1080/13573322.2011.607951

[87] Omar-Fauzee, M., Nazarudin, M., Saputra, Y., Sutresna, N., Taweesuk, D., Chansem, W., et al. (2012) The Strategies for Character Building through Sports Participation. International Journal of Academic Research in Business and Social Sciences, 3, 48-58.

[88] Côté, J., Baker, J. and Abernethy, B. (2007) Practice and Play in the Development of Sport Expertise. In: Handbook of Sport Psychology, 3rd Edition, Wiley, Hoboken, 184-202. https://doi.org/10.1002/9781118270011.ch8

[89] Bailey, R., Collins, D., Ford, P., Mac Namara, Á., Toms, M. and Pearce, G. (2010) Participant Development in Sport: An Academic Review. Sports Coach UK, 4, $1-134$.

[90] Baker, J., Cote, J. and Abernethy, B. (2003) Sport-Specific Practice and the Development of Expert Decision-Making in Team Ball Sports. Journal of Applied Sport Psychology, 15, 12-25. https://doi.org/10.1080/10413200305400

[91] Hill, G.M. (1993) Youth Sport Participation of Professional Baseball Players. Sociology of Sport Journal, 10, 107-114. https://doi.org/10.1123/ssj.10.1.107

[92] Bloom, B.S. (1985) Developing Talent in Young People. Ballantine, New York.

[93] Baker, J., Horton, S., Robertson-Wilson, J. and Wall, M. (2003) Nurturing Sport Expertise: Factors Influencing the Development of Elite Athlete. Journal of Sports Science \& Medicine, $2,1$.

[94] Coalter, F. (2010) The Politics of Sport-for-Development: Limited Focus Programmes and Broad Gauge Problems? International Review for the Sociology of Sport, 45, 295-314. https://doi.org/10.1177/1012690210366791

[95] Coalter, F.A. (2007) A Wider Social Role for Sport: Who's Keeping the Score? Taylor \& Francis, London.

[96] Larson, R.W., Hansen, D.M. and Moneta, G. (2006) Differing Profiles of Developmental Experiences across Types of Organized Youth Activities. Developmental Psychology, 42, 849-863. https://doi.org/10.1037/0012-1649.42.5.849

[97] Fraser-Thomas, J.L., Côté, J. and Deakin, J. (2005) Youth Sport Programs: An Avenue to Foster Positive Youth Development. Physical Education \& Sport Pedagogy, 10, 19-40. https://doi.org/10.1080/1740898042000334890

[98] Cote, J., Turnnidge, J. and Evans, M.B. (2014) The Dynamic Process of Development through Sport. Kinesiologica Slovenica, 20, 14-26.

[99] Holt, N.L., Neely, K.C., Slater, L.G., Camiré, M., Côté, J., Fraser-Thomas, J., et al. (2017) A Grounded Theory of Positive Youth Development through Sport Based on Results from a Qualitative Meta-Study. International Review of Sport and Exercise Psychology, 10, 1-49. https://doi.org/10.1080/1750984X.2016.1180704

[100] Ste-Marie, D.M., Vertes, K., Rymal, A.M. and Martini, R. (2011) Feedforward 
Self-Modeling Enhances Skill Acquisition in Children Learning Trampoline Skills. Frontiers in Psychology, 2, Article 155. https://doi.org/10.3389/fpsyg.2011.00155

[101] Renshaw, I., Chow, J.Y., Davids, K. and Hammond, J. (2010) A Constraints-Led Perspective to Understanding Skill Acquisition and Game Play: A Basis for Integration of Motor Learning Theory and Physical Education Praxis? Physical Education \& Sport Pedagogy, 15, 117-137. https://doi.org/10.1080/17408980902791586

[102] Eime, R.M., Young, J.A., Harvey, J.T., Charity, M.J. and Payne, W.R. (2013) A Systematic Review of the Psychological and Social Benefits of Participation in Sport for Children and Adolescents: Informing Development of a Conceptual Model of Health through Sport. International Journal of Behavioral Nutrition and Physical Activity, 10, Article No. 98. https://doi.org/10.1186/1479-5868-10-98

[103] Gould, D., Voelker, D.K. and Griffes, K. (2013) Best Coaching Practices for Developing Team Captains. The Sport Psychologist, 27, 13-26. https://doi.org/10.1123/tsp.27.1.13

[104] Holt, N.L. and Neely, K.C. (2011) Positive Youth Development through Sport: A Review. Revista de Iberoamericanade Psicologia del Ejercicioy el Deporte, 6, 299-316.

[105] Pierce, S., Gould, D. and Camiré, M. (2017) Definition and Model of Life Skills Transfer. International Review of Sport and Exercise Psychology, 10, 186-211. https://doi.org/10.1080/1750984X.2016.1199727

[106] Zeldin, S., Christens, B.D. and Powers, J.L. (2013) The Psychology and Practice of Youth-Adult Partnership: Bridging Generations for Youth Development and Community Change. American Journal of Community Psychology, 51, 385-397. https://doi.org/10.1007/s10464-012-9558-y

[107] Camino, L.A. (2000) Youth-Adult Partnerships: Entering New Territory in Community Work and Research. Applied Developmental Science, 4, 11-20. https://doi.org/10.1207/S1532480XADS04Suppl_2

[108] Mitra, D.L. (2009) Collaborating with Students: Building Youth-Adult Partnerships in Schools. American Journal of Education, 115, 407-436. https://doi.org/10.1086/597488

[109] Anderson, K.S. and Sandmann, L. (2009) Toward a Model of Empowering Practices in Youth-Adult Partnerships. Journal of Extension, 47, 1-8.

[110] Krauss, S.E., Collura, J., Zeldin, S., Ortega, A., Abdullah, H. and Sulaiman, A.H. (2014) Youth-Adult Partnership: Exploring Contributions to Empowerment, Agency and Community Connections in Malaysian Youth Programs. Journal of Youth and Adolescence, 43, 1550-1562. https://doi.org/10.1007/s10964-013-0027-1

[111] Camino, L. (2005) Pitfalls and Promising Practices of Youth-Adult Partnerships: An Evaluator's Reflections. Journal of Community Psychology, 33, 75-85.

https://doi.org/10.1002/jcop.20043

[112] Sanders, E.B.-N. and Stappers, P.J. (2008) Co-Creation and the New Landscapes of Design. CoDesign, 4, 5-18. https://doi.org/10.1080/15710880701875068

[113] Sanders, L. and Simons, G. (2009) A Social Vision for Value Co-Creation in Design. Technology Information Management Review, December, 1-5.

[114] Bovill, C. (2014) An Investigation of Co-Created Curricula within Higher Education in the UK, Ireland and the USA. Innovations in Education and Teaching International, 51, 15-25. https://doi.org/10.1080/14703297.2013.770264

[115] Reay, S., Collier, G., Kennedy-Good, J., Old, A., Douglas, R. and Bill, A. (2017) Designing the Future of Healthcare Together: Prototyping a Hospital Co-Design 
Space. CoDesign, 13, 227-244. https://doi.org/10.1080/15710882.2016.1160127

[116] Gruber, M., de Leon, N., George, G. and Thompson, P. (2015) Managing by Design. Academy of Management Journal, 58, 1-7. https://doi.org/10.5465/amj.2015.4001

[117] Pedersen, J. and Burr, J. (2000) Games and Movies: Towards Innovative Co-Design with Users. In: Collaborative Design, Springer, London, 93-100. https://doi.org/10.1007/978-1-4471-0779-8_9

[118] Vettraino, E., Linds, W. and Jindal-Snape, D. (2017) Embodied Voices: Using Applied Theatre for Co-Creation with Marginalised Youth. Emotional and Behavioural Difficulties, 22, 79-95. https://doi.org/10.1080/13632752.2017.1287348

[119] Bandura, A. (1986) Social Foundations of Thought and Theory: A Social Cognitive Theory. Prentice-Hall, Englewood Cliffs.

[120] Bandura, A., Ross, D. and Ross, S.A. (1961) Transmission of Aggression through Imitation of Aggressive Models. Journal of Abnormal and Social Psychology, 63, 575-582. https://doi.org/10.1037/h0045925

[121] Gilligan, R. (2000) Adversity, Resilience and Young People: The Protective Value of Positive School and Spare Time Experiences. Children Society, 14, 37-47. https://doi.org/10.1111/j.1099-0860.2000.tb00149.x

[122] Surowiecki, J. (2005) The Wisdom of Crowds. Reprint Edition, Anchor, New York, $336 \mathrm{p}$.

[123] Roth, J.L. and Brooks-Gunn, J. (2003) What Exactly Is a Youth Development Program? Answers from Research and Practice. Applied Developmental Science, 7, 94-111. https://doi.org/10.1207/S1532480XADS0702_6

[124] Johnson, J. (1997) Generalizability in Qualitative Research: Excavating the Discourse. In: Compleing a Qualitative Project. Details and Dialogue, Sage Publications, Thousand Oaks, 191-208.

[125] Kearney, M.H. (2001) Levels and Applications of Qualitative Research Evidence. Research in Nursing \& Health, 24, 145-153. https://doi.org/10.1002/nur.1017

[126] Krauss, S. (2005) Research Paradigms and Meaning Making: A Primer. The Qualitative Report, 10, 758-770.

[127] Cohen, D. and Crabtree, B. (2006) Qualitative Research Guidelines Project. Robert Wood Johnson Foundation, Princeton. http://www.qualres.org 